\title{
Greenhouse gas observations from the Northeast Corridor tower network
}

\author{
Anna Karion ${ }^{1}$, William Callahan ${ }^{2}$, Michael Stock ${ }^{2}$, Steve Prinzivalli ${ }^{2}$, Kristal R. Verhulst ${ }^{3}$, Jooil Kim ${ }^{4}$, \\ Peter K. Salameh ${ }^{4}$, Israel Lopez-Coto ${ }^{5}$, and James Whetstone ${ }^{1}$ \\ ${ }^{1}$ Special Programs Office, National Institute of Standards and Technology, Gaithersburg, MD, USA \\ ${ }^{2}$ Earth Networks, Inc., Germantown, MD, USA \\ ${ }^{3}$ NASA Jet Propulsion Laboratory, California Institute of Technology, Pasadena, CA, USA \\ ${ }^{4}$ Scripps Institution of Oceanography, University of California San Diego, La Jolla, CA, USA \\ ${ }^{5}$ Engineering Laboratory, National Institute of Standards and Technology, Gaithersburg, MD, USA \\ Correspondence: Anna Karion (anna.karion@nist.gov)
}

Received: 23 October 2019 - Discussion started: 28 November 2019

Revised: 10 February 2020 - Accepted: 21 February 2020 - Published: 25 March 2020

\begin{abstract}
We present the organization, structure, instrumentation, and measurements of the Northeast Corridor greenhouse gas observation network. This network of tower-based in situ carbon dioxide and methane observation stations was established in 2015 with the goal of quantifying emissions of these gases in urban areas in the northeastern United States. A specific focus of the network is the cities of Baltimore, MD, and Washington, DC, USA, with a high density of observation stations in these two urban areas. Additional observation stations are scattered throughout the northeastern US, established to complement other existing urban and regional networks and to investigate emissions throughout this complex region with a high population density and multiple metropolitan areas. Data described in this paper are archived at the National Institute of Standards and Technology and can be found at https://doi.org/10.18434/M32126 (Karion et al., 2019).
\end{abstract}

\section{Introduction}

As the population of cities grows globally due to trends toward urbanization, so does their relative contribution to global anthropogenic greenhouse gas (GHG) budgets (Edenhofer et al., 2014; O'Neill et al., 2010). City governments are making commitments to reduce their emissions of GHGs through various sustainability and efficiency measures and coordination with organizations like the C40 Climate Leadership Group (http://www.c40.org, last access: 23 March 2020), the Global Covenant of Mayors for Climate and Energy (https://www.globalcovenantofmayors.org, last access: 23 March 2020), and others. These organizations require individual cities to conform to certain standardized mechanisms and practices for reporting their carbon emissions. City governments rely on inventories compiled using data on fuel use, energy usage, etc., to estimate their total emissions and changes over time and to determine the efficacy of various emissions mitigation policies. Analysis of atmospheric measurements provides additional useful information to such efforts, by confirming inventory estimates (Sargent et al., 2018; Lauvaux et al., 2016), detecting trends (Mitchell et al., 2018), or estimating emissions that are not well quantified using inventory methods, such as methane emissions (McKain et al., 2015; Ren et al., 2018; Lamb et al., 2016; Yadav et al., 2019). Several urban top-down measurement efforts are underway in various cities that include networks of observations, often in situ $\mathrm{CO}_{2}$ and $\mathrm{CH}_{4}$ measurements from rooftops or towers (Verhulst et al., 2017; XuerefRemy et al., 2018; Bares et al., 2019) or using other long-path and remote sensing methods (Waxman et al., 2019; Hedelius et al., 2018; Wong et al., 2016; Pillai et al., 2016).

The National Institute of Standards and Technology (NIST) has partnered with other federal, private, and academic institutions to establish three urban test beds in the United States: the Indianapolis Flux Experiment (INFLUX, http://influx.psu.edu, last access: 
23 March 2020), the Los Angeles Megacities Carbon Project (http://megacities.jpl.nasa.gov, last access: 23 March 2020), and the Northeast Corridor (NEC, http: //www.nist.gov/topics/northeast-corridor-urban-test-bed, last access: 23 March 2020). The goals of the urban test beds are to develop and refine techniques for estimating greenhouse gas emissions from cities and to understand the uncertainty of emissions estimates at various spatial and temporal scales (e.g., whole city annual emissions vs. $1 \mathrm{~km}$ weekly emissions). Recent results from the longest-running test bed, INFLUX, show that whole city emissions can be estimated using three different methods to within $7 \%$ (Turnbull et al., 2019).

The Northeast Corridor (NEC) was established in 2015 as the third NIST urban test bed. The goals for this project are to demonstrate that top-down atmospheric emissions estimation methods can be used in a domain that is complicated by many upwind and nearby emissions sources in the form of surrounding urban areas. The objective is to isolate the anthropogenic GHG emissions from urban areas along the US East Coast from many confounding sources upwind (cities, oil and gas development, coal mines, and power plants) and from the large biological $\mathrm{CO}_{2}$ signal from the highly productive forests nearby and within the cities. The presence of highly vegetated areas such as urban parks, local agriculture, and managed lawns is expected to dominate the $\mathrm{CO}_{2}$ signal in summertime, as has been found in Boston, MA (Sargent et al., 2018). The NEC project has a current focus on the urban areas of Washington, DC, and Baltimore, MD, USA, with existing plans to expand northward to cover the entire urbanized corridor of the northeastern US, including the cities of Philadelphia and New York City, and eventually linking up with existing measurement stations in Boston, MA (McKain et al., 2015; Sargent et al., 2018).

The NEC project includes multiple measurement and analysis components. The backbone of the NEC project is a network of in situ $\mathrm{CO}_{2}$ and $\mathrm{CH}_{4}$ observation stations with continuous high-accuracy measurements of these two greenhouse gases. In addition, periodic flight campaigns of multiple weeks each year are conducted by the University of Maryland (FLAGG-MD, http://www.atmos.umd.edu/ flaggmd, last access: 23 March 2020) and Purdue University (https://www.science.purdue.edu/shepson/research/ ALARGreenhouseGas/, last access: 23 March 2020), focusing on wintertime observations of $\mathrm{CO}_{2}, \mathrm{CH}_{4}, \mathrm{CO}$, $\mathrm{O}_{3}, \mathrm{SO}_{2}$, and $\mathrm{NO}_{2}$ from instrumented aircraft (Ren et al., 2018; Salmon et al., 2018; Lopez-Coto et al., 2020a). The use of low-cost $\mathrm{CO}_{2}$ sensors is also being investigated in Washington, DC, with work focusing on calibration and determination of long-term stability of inexpensive nondispersive infrared (NDIR) sensors with potential for use in $\mathrm{CO}_{2}$ data assimilation techniques (Martin et al., 2017). The NEC project also includes an extensive modeling component. First, high-resolution meteorological modeling (using the Weather Research and Forecast (WRF) model) is being conducted (Lopez-Coto et al., 2020b), with output coupled to Lagrangian dispersion models such as STILT (Lin et al., 2003; Nehrkorn et al., 2010) and HYSPLIT (Stein et al., 2015). These transport and dispersion models are used to interpret observations from both aircraft and tower stations and in atmospheric inverse analyses to estimate fluxes of $\mathrm{CO}_{2}$ and $\mathrm{CH}_{4}$ from the cities of Washington, DC, and Baltimore, MD (Lopez-Coto et al., 2020a; Huang et al., 2019). A high-resolution fossil fuel $\mathrm{CO}_{2}$ inventory, Hestia, is also being developed for this project (Gurney et al., 2012, 2019).

Here we focus on the high-accuracy tower observation network and associated data collection and processing methods. Section 2 describes the tower network design and characterizes the different site locations; Sect. 3 describes the measurement methods, instrumentation, and calibration; Sect. 4 presents the uncertainty derivation for the measurements; and, finally, Sect. 5 presents some of the observations from the current record.

\section{Network design and site characterization}

The NEC project includes 29 observation stations, all managed and operated by Earth Networks, Inc. ${ }^{1}$ (http://www. earthnetworks.com/why-us/networks/greenhouse-gas, last access: 23 March 2020). A total of 10 stations were existing Earth Networks (EN) measurement sites in the northeastern US that became part of the NEC project in 2015. A total of 19 stations were established (or will be established) specifically for the NEC project, with site locations identified by NIST. A total of 16 of these station locations were chosen to be used for emissions estimation in a domain around Baltimore and Washington, DC (red boundary, Fig. 1), using inverse modeling techniques (Lopez-Coto et al., 2017; Mueller et al., 2018). Three others are in Mashpee, MA, Philadelphia, PA, and Waterford Works, NJ. As of publication, 14 of these 19 have been established, with delays occurring due to difficulty finding suitable tower locations to agree to house the systems. The hardware and software operating at all the sites is identical with few exceptions as noted in the text.

The initial design of the core urban Baltimore-Washington network was focused on optimizing tower site locations with the goal of reducing uncertainty in estimating anthropogenic $\mathrm{CO}_{2}$ emissions from Washington, DC, and Baltimore using an atmospheric inversion model (Lopez-Coto et al., 2017). A total of 12 communications towers were identified as part

\footnotetext{
${ }^{1}$ Certain commercial equipment, instruments, or materials are identified in this paper in order to specify the experimental procedure adequately. Such identification is not intended to imply recommendation or endorsement by the National Institute of Standards and Technology nor is it intended to imply that the materials or equipment identified are necessarily the best available for the purpose.
} 

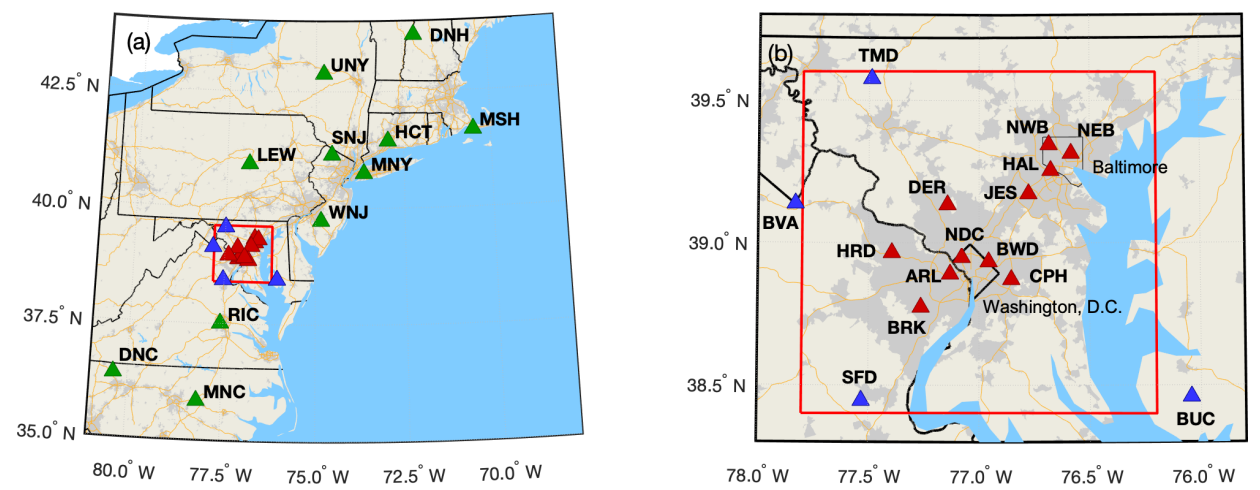

Figure 1. Locations of Northeast Corridor (NEC) established tower-based observations, corresponding to Table 1. The red rectangle indicates the modeling analysis domain. Light grey shading indicates census-designated urban areas, yellow lines are interstate highways, and black boundaries are state lines, with a thinner black line showing the City of Baltimore. Green triangles indicate regional sites, red triangles indicate urban sites, and blue triangles are more rural or background sites surrounding the Washington-Baltimore domain. (a) Regional map. (b) Inset focusing on Washington, DC, and Baltimore, MD. All map data layers were obtained from either Natural Earth (http://naturalearthdata.com, last access: 23 March 2020) or U.S. Government sources (http://www.census.gov, last access: 23 March 2020) and are in the public domain.

of that study as ideal locations for measurements. Actual measurement sites were sometimes established at locations near the ideal study location, usually due to logistical difficulties obtaining leases at the ideal tower sites. A second design study determined ideal locations for background stations, i.e., observation station locations that would aid in the determination of background $\mathrm{CO}_{2}$ entering the analysis domain (Mueller et al., 2018). Four stations were identified as part of that study; an existing EN site in Bucktown, MD, serves as a fifth background station southeast of the analysis domain (Fig. 1). Although inlet heights were desired to be $100 \mathrm{~m}$ above ground level (a.g.l.), often shorter towers were used due to the lack of availability of tall towers in ideal locations; the shortest tower in this network has the uppermost inlet at $38 \mathrm{~m}$ a.g.l. (HRD). Table 1 indicates details and locations of each site.

The stations in Table 1 are all situated in areas with different land use. Even among the Washington, DC, and Baltimore area urban stations, the degree of urban intensity varies, from densely urbanized areas (such as northeastern Baltimore, NEB) to dense and moderately developed suburbs (such as Capitol Heights, CPH, and Derwood, DER, both suburbs of Washington, DC, located in Maryland). Figure 2 indicates the intensity of development from the US Geological Survey (USGS) 2016 National Land Cover Database (Yang et al., 2018) surrounding each urban station in the Washington, DC, and Baltimore network.

Similar variability in land cover for the regional stations exists, as indicated in Fig. 3. The sites established to characterize background conditions for the urban network in Washington, DC, and Baltimore (SFD, TMD, BUC) are in areas with little development: SFD and TMD are both in forested regions, while BUC is near the Chesapeake Bay and large wetland areas. The other regional sites span a range of land cover types from urban (MNY in New York City and RIC

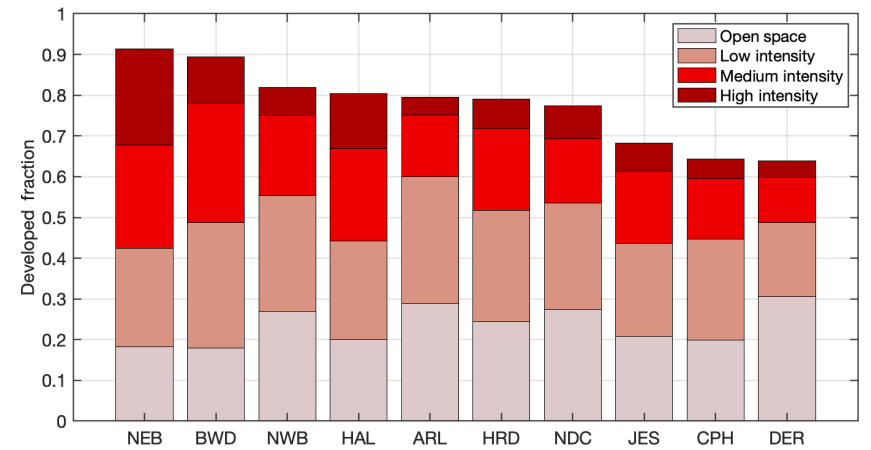

Figure 2. Fraction of developed land cover (from the 2016 National Land Cover Database (NLCD); Yang et al., 2018) within $5 \mathrm{~km}$ of each observation station in the urban regions of Washington, DC, and Baltimore, MD.

in Richmond, VA), to mostly rural and forested (DNH in Durham, NH).

\section{Carbon dioxide, methane, and carbon monoxide measurements, instrumentation, and calibration}

\subsection{Instrumentation}

The instrumentation contained in the Earth Networks (EN) system module has been described elsewhere (Welp et al., 2013; Verhulst et al., 2017); we will summarize the system here but refer the reader to those publications for further details, including additional equipment and part numbers. Figure 4 indicates the plumbing diagram of the typical tower setup. Three inlet lines reach from the sampling location on the tower into the equipment housed in a full-size rack inside a shed at the base of the tower. Typically, two inlet lines sample from the topmost level and one line samples from a lower 
Table 1. Northeast Corridor site list. Sites lacking location information are still in the planning phase, with no assigned site code or exact location.

\begin{tabular}{|c|c|c|c|c|c|c|c|c|}
\hline Site Code & EN site ID & Location & Latitude & Longitude & Elev. (m) & Intake heights (m) & Measurements & Est. (mm/yyyy) \\
\hline \multicolumn{9}{|c|}{ Northeast Corridor regional sites (12) } \\
\hline DNC & GHG12 & Danbury, NC & 36.3769 & -80.3689 & 703 & 100,50 & $\mathrm{CO}_{2}, \mathrm{CH}_{4}$ & $01 / 2015^{*}$ \\
\hline MNC & GHG15 & Middlesex, NC & 35.8313 & -78.1453 & 74 & 213,50 & $\mathrm{CO}_{2}, \mathrm{CH}_{4}$ & $01 / 2015^{*}$ \\
\hline RIC & GHG18 & Richmond, VA & 37.5088 & -77.5761 & 104 & 95,50 & $\mathrm{CO}_{2}, \mathrm{CH}_{4}$ & $01 / 2015^{*}$ \\
\hline SNJ & GHG19 & Stockholm, NJ & 41.1436 & -74.5387 & 406 & 53,42 & $\mathrm{CO}_{2}, \mathrm{CH}_{4}$ & $01 / 2015^{*}$ \\
\hline $\mathrm{HCT}$ & GHG21 & Hamden, CT & 41.4337 & -72.9452 & 204 & 100,50 & $\mathrm{CO}_{2}, \mathrm{CH}_{4}$ & $01 / 2015^{*}$ \\
\hline LEW & GHG25 & Lewisburg, PA & 40.9446 & -76.8789 & 166 & 95,50 & $\mathrm{CO}_{2}, \mathrm{CH}_{4}$ & $01 / 2015^{*}$ \\
\hline DNH & GHG35 & Durham, NH & 43.7089 & -72.1541 & 559 & 100,50 & $\mathrm{CO}_{2}, \mathrm{CH}_{4}$ & $01 / 2015^{*}$ \\
\hline UNY & GHG38 & Utica, NY & 42.8790 & -74.7852 & 483 & 45,35 & $\mathrm{CO}_{2}, \mathrm{CH}_{4}$ & $01 / 2015^{*}$ \\
\hline MNY & GHG47 & Mineola, NY & 40.7495 & -73.6384 & 34 & 90,50 & $\mathrm{CO}_{2}, \mathrm{CH}_{4}$ & $01 / 2015^{*}$ \\
\hline MSH & GHG54 & Mashpee, MA & 41.6567 & -70.4975 & 32 & 46,25 & $\mathrm{CO}_{2}, \mathrm{CH}_{4}, \mathrm{CO}$ & $12 / 2015$ \\
\hline WNJ & GHG69 & $\begin{array}{l}\text { Waterford Works, NJ } \\
\text { Philadelphia, PA }\end{array}$ & 39.7288 & -74.8441 & 33 & $241,201,151,98,43$ & $\begin{array}{l}\mathrm{CO}_{2}, \mathrm{CH}_{4} \\
\mathrm{CO}_{2}, \mathrm{CH}_{4}\end{array}$ & Planned 2020 \\
\hline \multicolumn{9}{|c|}{ Washington, DC, and Baltimore urban sites (12) } \\
\hline HAL & GHG48 & Halethorpe, MD & 39.2552 & -76.6753 & 70 & 58,29 & $\mathrm{CO}_{2}, \mathrm{CH}_{4}$ & $10 / 2015$ \\
\hline ARL & GHG55 & Arlington, VA & 38.8917 & -77.1317 & 111 & 92,50 & $\mathrm{CO}_{2}, \mathrm{CH}_{4}$ & $01 / 2016$ \\
\hline NDC & GHG56 & Northwestern DC & 38.9499 & -77.0796 & 128 & 91,45 & $\mathrm{CO}_{2}, \mathrm{CH}_{4}$ & $12 / 2015$ \\
\hline NWB & GHG58 & NW Baltimore, MD & 39.3445 & -76.6851 & 135 & 55,27 & $\mathrm{CO}_{2}, \mathrm{CH}_{4}$ & $09 / 2016$ \\
\hline NEB & GHG59 & NE Baltimore, MD & 39.3154 & -76.5830 & 44 & 67,50 & $\mathrm{CO}_{2}, \mathrm{CH}_{4}$ & $09 / 2016$ \\
\hline JES & GHG60 & Jessup, MD & 39.1723 & -76.7765 & 67 & 91,49 & $\mathrm{CO}_{2}, \mathrm{CH}_{4}$ & $05 / 2016$ \\
\hline DER & GHG63 & Derwood, MD & 39.1347 & -77.1419 & 125 & 54,30 & $\mathrm{CO}_{2}, \mathrm{CH}_{4}$ & $05 / 2018$ \\
\hline $\mathrm{CPH}$ & GHG66 & Capitol Heights, MD & 38.8707 & -76.8537 & 50 & 44,25 & $\mathrm{CO}_{2}, \mathrm{CH}_{4}$ & $02 / 2018$ \\
\hline HRD & GHG67 & Herndon, VA & 38.9663 & -77.3935 & 120 & 38,27 & $\mathrm{CO}_{2}, \mathrm{CH}_{4}$ & $10 / 2017$ \\
\hline BWD & GHG64 & Brentwood, MD & 38.9343 & -76.9556 & 17 & 51,33 & $\mathrm{CO}_{2}, \mathrm{CH}_{4}$ & $08 / 2018$ \\
\hline BRK & GHG68 & $\begin{array}{l}\text { Burke, VA } \\
\text { Southeastern DC }\end{array}$ & 38.7742 & -77.2631 & 111 & 40,24 & $\begin{array}{l}\mathrm{CO}_{2}, \mathrm{CH}_{4} \\
\mathrm{CO}_{2}, \mathrm{CH}_{4}\end{array}$ & Planned 2020 \\
\hline \multicolumn{9}{|c|}{ Washington, DC, and Baltimore background sites (5) } \\
\hline BUC & GHG01 & Bucktown, MD & 38.4597 & -76.0430 & 3 & 75,46 & $\mathrm{CO}_{2}, \mathrm{CH}_{4}$ & $01 / 2015^{*}$ \\
\hline TMD & GHG61 & Thurmont, MD & 39.5768 & -77.4881 & 561 & 113,49 & $\mathrm{CO}_{2}, \mathrm{CH}_{4}$ & $05 / 2017$ \\
\hline SFD & GHG65 & Stafford, VA & 38.4459 & -77.5300 & 77 & $152,100,50$ & $\mathrm{CO}_{2}, \mathrm{CH}_{4}$ & $07 / 2017$ \\
\hline BVA & GHG62 & $\begin{array}{l}\text { Bluemont, VA } \\
\text { Delta, PA }\end{array}$ & 39.1379 & -77.8326 & 486 & 111,50 & $\begin{array}{l}\mathrm{CO}_{2}, \mathrm{CH}_{4} \\
\mathrm{CO}_{2}, \mathrm{CH}_{4}\end{array}$ & $02 / 2020$ \\
\hline
\end{tabular}

* If a station was established prior to the beginning of the project, its establishment date is listed as 01/2015, the start date of the project. Data prior to this date are not part of the NIST data release.

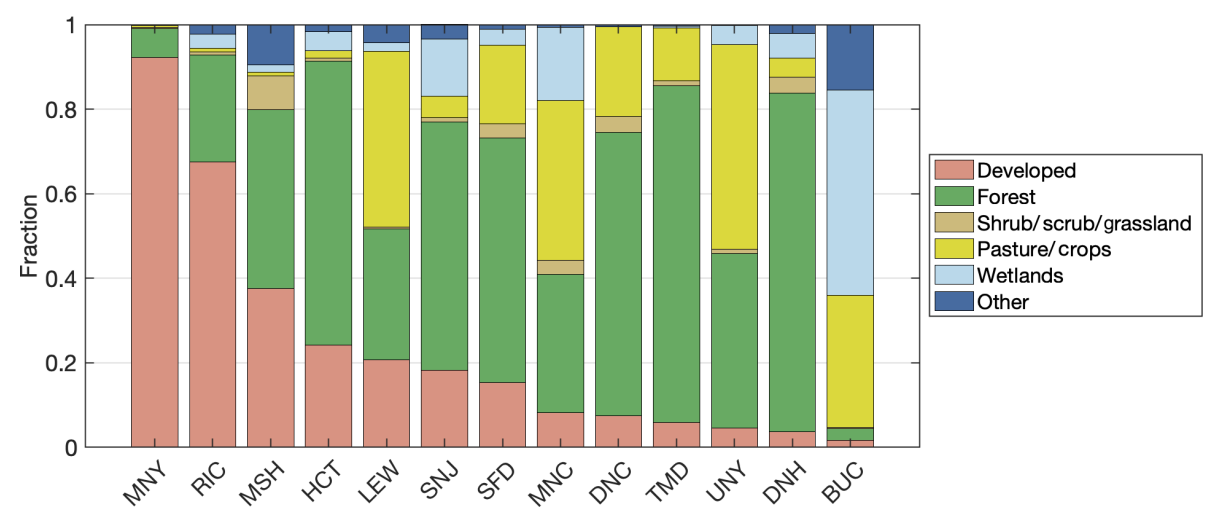

Figure 3. Average fraction of land cover type within $5 \mathrm{~km}$ of regional tower sites in the Northeast Corridor network, in order of decreasingly developed land. Several NLCD classifications have been grouped for clarity (e.g., "developed" includes open spaces and low-, medium-, and high-intensity developed land). SFD, TMD, and BUC are sites established to help characterize background conditions for the Washington, DC, and Baltimore urban network. 
level on the tower. Stafford, VA (SFD), is one exception with inlets at three different levels $(50,100$, and $152 \mathrm{~m})$, and a planned tower in New Jersey (Waterford Works) will have five inlet height levels, as indicated in Table 1. At some sites there was no space to house the equipment in existing structures, thus small single- or double-rack sized enclosures were purchased and installed. Air is pulled through a filter into the inlet lines $(0.953 \mathrm{~cm}$, i.e., $0.375 \mathrm{in}$., OD Synflex 1300) that are continuously flushed at $\sim 10 \mathrm{~L} \mathrm{~min}^{-1}$ by aquarium pumps (Alita AL-6SA). The three air lines are connected to a rotary multi-port valve (MPV; eight-port, VICI, Valco Instruments Co. Inc.) housed within a sample control box (calibration box). Two or three calibration standards are also connected to the MPV with $0.156 \mathrm{~cm}$ (0.0625 in.) OD stainless steel tubing. The control system for the MPV directs the air stream to the analyzer cycling every $20 \mathrm{~min}$ through each of the three inlet lines so that each inlet is sampled at least once an hour and every $22 \mathrm{~h}$ through each standard (Sect. 3.2). The common port of the MPV is connected to a pressure controller that reduces the pressure to $80 \mathrm{kPa}(800 \mathrm{mb})$, after which the sample (either ambient air or air from a standard gas cylinder) enters a $183 \mathrm{~cm}$ long Nafion dryer (Permapure, Inc., model MD-050-72S-1), where it is dried to a water vapor mole fraction of $\sim 0.1 \%$ prior to flowing through the cavity ring-down spectroscopic (CRDS) analyzer (Picarro, Inc., Model 2301). The lower-than-ambient inlet pressure of $80 \mathrm{kPa}$ is prescribed in order to lower the flow rate of the analyzer to $\sim 70$ standard $\mathrm{cm}^{3} \mathrm{~min}^{-1}$. At Mashpee, MA (MSH), a CRDS Picarro Model 2401 analyzer is operational, and this is the only site currently also measuring carbon monoxide (CO) in addition to $\mathrm{CO}_{2}$ and $\mathrm{CH}_{4}$. The CRDS analyzers report measurements of dry air mole fraction of each gas in air, also known as the mole fraction, i.e., moles of the trace gas per mole of dry air. Throughout, we refer to these measurements in units of $\mu \mathrm{mol} \mathrm{mol}^{-1}$ for $\mathrm{CO}_{2}$ and $\mathrm{nmol} \mathrm{mol}^{-1}$ for $\mathrm{CH}_{4}$ and $\mathrm{CO}$, following the $\mathrm{SI}$ recommendations (Bureau International des Poids et Mesures, 2019). Software (GCWerks, Inc.) installed on a separate mini-PC at each site controls the run cycle and the MPV selection valve. The data are collected on this computer and sent to the central EN data server, also running GCWerks. All data are processed on the central EN data server but additional post-processing and uncertainty assignment to hourly observations is performed at NIST. As recommended by the World Meteorological Organization (WMO), the software has the capability of reprocessing all the data from the original raw files and thus can accommodate any changes to the assigned values of the standards (due to a reference-scale update, for example) at any time (WMO, 2018).

\subsection{Calibration cylinders}

When the Earth Networks GHG monitoring system was established in 2011, each site hosted two calibration cylinders (standards) with ambient level dry air mole fractions as part of the original system design. This continues to be the case at most NEC sites. At the NEC sites, these standards have values close to $400 \mu \mathrm{mol} \mathrm{mol}^{-1}$ dry air $\mathrm{CO}_{2}$, $1890 \mathrm{nmol} \mathrm{mol}^{-1}$ dry air $\mathrm{CH}_{4}$, and $115 \mathrm{nmol} \mathrm{mol}^{-1}$ dry air $\mathrm{CO}$ (at MSH only) and are sampled by the analyzer periodically, in a sequence identical to that described for the Los Angeles Megacity network by Verhulst et al. (2017). The standards are purchased from the WMO Central Calibration Laboratory (CCL), the National Oceanographic and Atmospheric Administration's Earth System Research Laboratory (NOAA/ESRL) Global Monitoring Division in Boulder, CO, USA, where they have been calibrated on the WMO scales (X2007 for $\mathrm{CO}_{2}, \mathrm{X} 2004 \mathrm{~A}$ for $\mathrm{CH}_{4}$, and X2014A for $\mathrm{CO}$, Zhao et al., 1997; Dlugokencky et al., 2005; Novelli et al., 2003). One of these two cylinders serves as a standard for calibration and drift-correction, while the second serves as a target tank or check standard. The target tank is used for data quality checks and uncertainty calculations (Sect. 4). The residual of the target tank (the rms difference between its value assignment when treated as an unknown and its reference value from NOAA) is a critical indicator of data quality and is monitored in order to alert the operators of any general problems in the system such as leaks, mistakes in the assignment of MPV ports, or drift in calibration tank value. In the field, all gas standards are sampled for 20 min every $22 \mathrm{~h}$. In data processing, the first $10 \mathrm{~min}$ of any tank run are filtered out to allow for the system equilibration, including flushing of the regulator and tubing. In some cases, when the standard runs were found not to equilibrate as quickly as desired, $15 \mathrm{~min}$ of data were filtered until the problem could be fixed (typically either contamination or inadequate regulator flushing). The first $10 \mathrm{~min}$ of the ambient air sample following a standard run are also filtered for equilibration, and the first $1 \mathrm{~min}$ of each $20 \mathrm{~min}$ ambient air run is filtered if it follows another ambient air run (i.e., an inlet switch). The longer flush time is desired for the standard runs because of the need to flush stagnant air remaining in the regulators and tubing when sampling from the cylinder, while the ambient air lines are continuously flushed.

At a few NEC sites (currently BWD and MSH, with more planned), a third gas cylinder is installed at the site to serve as a permanent high-concentration standard (referred to as the high standard), to improve calibration and reduce uncertainties. This standard typically contains air with a mole fraction of $\mathrm{CO}_{2}$ close to $500 \mu \mathrm{mol} \mathrm{mol}^{-1}, \mathrm{CH}_{4}$ at approximately 2300 to $2500 \mathrm{nmol} \mathrm{mol}^{-1}$ and at MSH, CO, near $320 \mathrm{nmol} \mathrm{mol}^{-1}$. At $\mathrm{MSH}$, this cylinder has been provided directly by NOAA/ESRL, while at BWD this cylinder was purchased as natural whole air from Scott-Marrin, Inc. (now Praxair). The Scott-Marrin air is stripped of its original trace gases $\left(\mathrm{CO}_{2}, \mathrm{CH}_{4}, \mathrm{CO}\right.$, hydrocarbons, etc.) with $\mathrm{CO}_{2}, \mathrm{CH}_{4}$, and $\mathrm{CO}$ added back in to prescribed values. Several such standards have been purchased with the intent of placing them at urban stations to serve as high standards after calibrating them onto the WMO scales. We note that because 


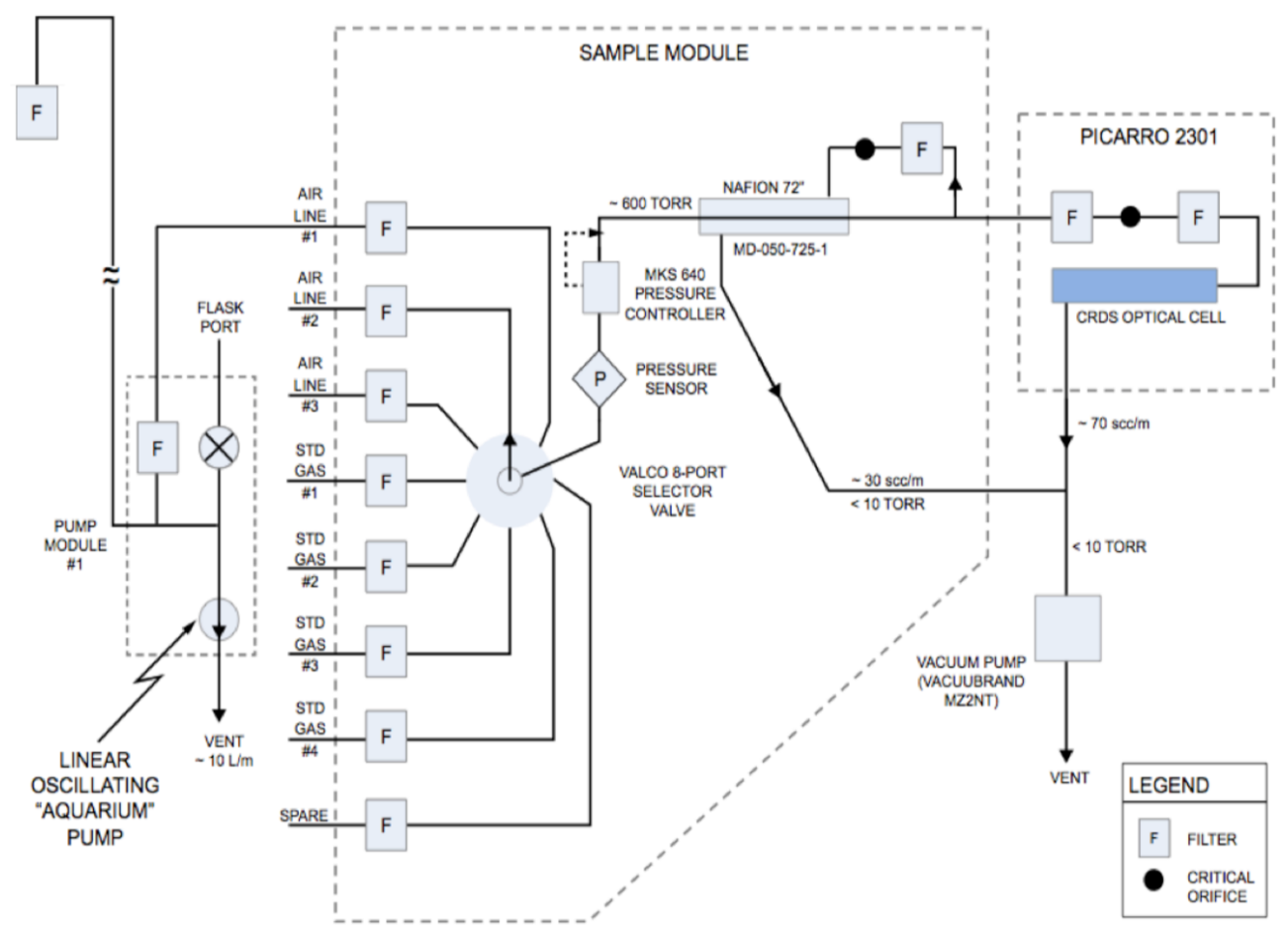

Figure 4. Plumbing diagram for the Earth Networks sampling system implemented at the NEC tower stations. Figure replicated from Fig. S1 in Verhulst et al. (2017), adapted from Welp et al. (2013).

they are being used together with NOAA/ESRL standards in the field, it is essential that these standards also be assigned values on the same scales. This calibration is transferred in the NIST laboratory using five standards calibrated and purchased from NOAA/ESRL. The $\mathrm{CO}_{2}$ in the Scott-Marrin cylinders is isotopically different (in terms of the ${ }^{12} \mathrm{C} /{ }^{13} \mathrm{C}$ ratio in $\mathrm{CO}_{2}$ ) from the ambient air tanks that are filled by NOAA/ESRL at Niwot Ridge, CO. However, the calibration is transferred from the NOAA standards to the Scott-Marrin gases using the same model (Picarro 2301) analyzer used in the field (i.e., measuring only ${ }^{12} \mathrm{CO}_{2}$ ) in the NIST laboratory, effectively canceling out the error that would be caused by this isotopic mismatch (Chen et al., 2010; Santoni et al., 2014). Thus, the $\mathrm{CO}_{2}$ values assigned by NIST to these standards are effectively the total dry air mole fraction of $\mathrm{CO}_{2}$ the cylinders would contain if they were isotopically similar to the NOAA cylinders.

Additional sites in the network also benefit from the improved two-point calibration method in cases where measurements of a high standard were performed prior to analyzer deployment (NWB, NEB, JES, TMD, CPH, and HRD). Prior to system installation at these sites, tests were conducted at the EN laboratory in which the designated analyzer was set up measuring the calibration standard, target standard, and a high-value standard at $\sim 490 \mu \mathrm{mol} \mathrm{mol}^{-1} \mathrm{CO}_{2}$ and $\sim 2560 \mathrm{nmol} \mathrm{mol}^{-1} \mathrm{CH}_{4}$ daily for several days (enough for 3-5 measurements of $20 \mathrm{~min}$ each). This single highstandard cylinder was also calibrated by and purchased from
NOAA/ESRL, with assigned values on the WMO scales. These laboratory tests allow the determination of the secondary correction to the instrument response or sensitivity, as described in Sect. 3.4.

The high-standard gas measurements are used to perform a secondary correction (referred to as a two-point calibration) (Sect. 3.4) to the original one-point calibration described by Verhulst et al. (2017) and in Sect. 3.3., reducing the uncertainty of the measurements. We note that while, in principle, a secondary correction is desirable, and the uncertainty is indeed reduced by its implementation (see Sect. 4.2), it remains quite small relative to the signals of interest in an urban network. Deployment of high standards at all sites has not yet occurred due to both costs and logistical and operational constraints; for example, at many sites the space available for the equipment is limited and prohibits the installation of a permanent third tank. Thus, we plan to implement a roundrobin procedure circulating additional standards at various values through the network to evaluate the calibrations and implement the secondary correction throughout the network. Although the current state of having two different calibration methods coexisting in the network is not ideal, we aim to implement the secondary correction throughout the network as soon as possible. 


\subsection{Drift correction and single-point calibration}

Here we describe the calibration and drift correction applied to all the mole fraction data. This single-point calibration uses only a single reference value, that of the calibration standard, to correct the raw mole fractions for each gas. The equations are identical (with a few nomenclature differences) to those found in Verhulst et al. (2017). In the following analysis, $X^{\prime}$ denotes a raw dry mole fraction measurement (i.e., a reported value from the CRDS analyzer after internal water vapor correction), while $X$ denotes a mole fraction after some correction has been applied (drift and/or calibration, as described in the equations below). A subscript cal indicates the main calibration standard (usually a single ambient level standard tank calibrated by NOAA/ESRL), subscript std indicates any other standard tank, tgt indicates a standard tank that is being used as a target, and the subscript air indicates the sample measurement. Note that within the GCWerks software, the meanings of the abbreviations cal and std are reversed from what is defined here; we choose to use the nomenclature by Verhulst et al. (2017) here for consistency with the literature. We note that we have changed some nomenclature slightly from Verhulst et al. (2017) for additional clarity and conciseness. We refer to the drift-corrected mole fraction as $X_{\mathrm{DC}}$, which is noted as $X_{\text {corr }}$ by Verhulst et al. (2017); we refer to the mole fraction after a secondary correction is applied as $X_{\mathrm{SC}}$. We also refer to the assigned mole fraction of a standard by the calibration laboratory as $C$ rather than $X_{\text {assign. }}$. We define the sensitivity $S$ to be the response of the analyzer or the ratio of the measured to the true value. In the case of the calibration tank, this is the ratio of the raw measured value, $X_{\text {cal }}^{\prime}$, to the assigned value of the standard by the calibration laboratory on the WMO scale for the given species, $C_{\text {cal }}$ :

$S=\frac{X_{\text {cal }}^{\prime}}{C_{\text {cal }}}$.

When only a single calibration standard is present (which is the case at most sites in the NEC network), this sensitivity is assumed to be constant across mole fractions but varying in time. The sensitivity for the calibration tank is thus interpolated in time and applied as a correction for the dry air mole fractions of $\mathrm{CO}_{2}$ and $\mathrm{CH}_{4}$ reported by the CRDS analyzer $\left(X_{\text {air }}^{\prime}\right)$ :

$X_{\mathrm{DC}, \text { air }}=\frac{X_{\mathrm{air}}^{\prime}}{S}$,

where $X_{\mathrm{DC} \text {,air }}$ is the drift-corrected air data. An alternative drift-correction is to use an additive offset, which is also interpolated in time, rather than a sensitivity for drift correction:

$X_{\mathrm{DC}, \mathrm{air}}=X_{\mathrm{air}}^{\prime}+\left(C_{\mathrm{cal}}-X_{\mathrm{cal}}^{\prime}\right)$.

Measurements from MSH that include a high-value cylinder suggest that the single-tank drift correction performs (very slightly) better using the ratio correction (Eq. 2) than the difference method (Eq. 3) for $\mathrm{CO}_{2}$ and $\mathrm{CH}_{4}$, while the opposite is true for $\mathrm{CO}$ (Fig. 5), thus the difference method is used only for $\mathrm{CO}$ in our network.

The calibration standard mole fractions are interpolated in time between subsequent runs in order to apply the above corrections to the air data, thus removing drift in the instrument's response. This drift-corrected fraction is reported in the hourly data files for sites and time periods where no range of concentrations is available in the standard tanks.

\subsection{Multiple-point calibration}

At some sites and for some time periods, a higher-molefraction standard is available, and a second-order correction can be made to the instrument sensitivity, accounting for the sensitivity being a function of mole fraction. Usually in the field, this correction employs only one additional standard, the higher-mole-fraction standard so that it is a two-point calibration; here we describe the general procedure for applying a correction using multiple standards at a range of concentrations. This is applied as a second-order correction to the drift-corrected air data. In general, if a range of standard concentrations is available, the correction in GCWerks is applied as described below. First, a drift-corrected sensitivity $\left(S_{\mathrm{DC}}\right)$ is calculated for each standard when it is measured, which is the ratio of the drift-corrected mole fraction of that standard ( $X_{\mathrm{DC} \text {,std }}$, based on Eq. 2 for $\mathrm{CO}_{2}$ and $\mathrm{CH}_{4}$ or Eq. 3 for $\mathrm{CO}$ ) to its assigned value:

$S_{\mathrm{DC}, \mathrm{std}}=\frac{X_{\mathrm{DC}, \mathrm{std}}}{C_{\mathrm{std}}}$.

For the calibration standard, this value is necessarily equal to 1 , but measurements of standard tanks with different assigned values indicate that the instrument sensitivity is dependent on the composition of the sample gas (in this case, the mole fraction of the standard tank). In laboratory calibrations, we find that the drift-corrected sensitivity defined in Eq. (4) is a linear function of the mole fraction ratio to the calibration gas $\left(X^{\prime} / X_{\text {cal }}^{\prime}\right)$, thus we use a linear fit to the range of standards to determine the slope $m$ and intercept $b$ :

$S_{\mathrm{DC}}=m\left(\frac{X^{\prime}}{X_{\mathrm{cal}}^{\prime}}\right)+b$.

In this fit, we force $m+b=1$ by fitting a slope $m$ and then setting $b=1-m$ in order to maintain the proper relationship for the calibration tank itself, when $S_{\mathrm{DC} \text {, cal }}=1$. Applying this fit to the air data, the final air mole fraction $X_{\mathrm{SC} \text {, air }}$ is determined from

$X_{\mathrm{SC}, \text { air }}=\left(\frac{X_{\mathrm{DC}, \text { air }}}{S_{\mathrm{DC}}}\right)$.

In the NEC tower network, there are no sites with multiple standard tanks at various concentrations. At several sites, 

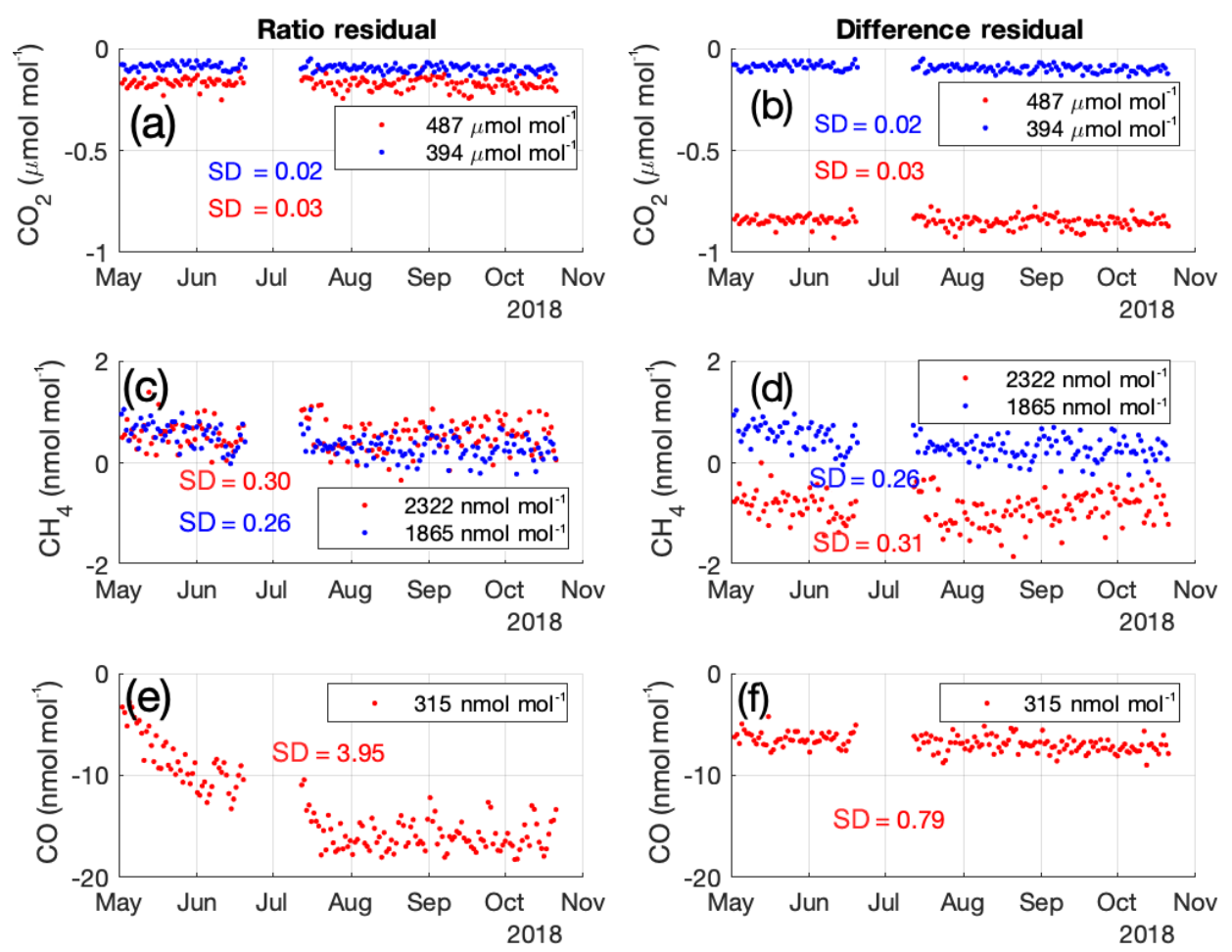

Figure 5. Time series of standard tank run residuals (i.e., $X_{\mathrm{DC}}-C$ ) for $\mathrm{CO}_{2}(\mathbf{a}, \mathbf{b}), \mathrm{CH}_{4}(\mathbf{c}, \mathbf{d})$, and $\mathrm{CO}(\mathbf{e}, \mathbf{f})$. $X_{\mathrm{DC}}$ is calculated using a single calibration tank (not shown) and the ratio method (Eq. 2) on the left (a, c, e) and the difference method (Eq. 3) on the right (b, d, f). Assigned tank values are shown in the legend; one tank was not calibrated for CO so only the residuals of the high-concentration tank at $315 \mathrm{nmol} \mathrm{mol}^{-1}$ are shown. The residual magnitude is smaller for $\mathrm{CO}_{2}$ and $\mathrm{CH}_{4}$ using the ratio method, but the standard deviations (variability) are similar using both methods. For CO, both the magnitude of the residual and the standard deviation are smaller using the difference equation; the ratio equation does not properly account for the drift in the analyzer at the start of the time series (May-June). Data shown are from MSH; a measurement gap exists in July.

there are measurements of a single high-concentration standard (hstd) in addition to the calibration and target standards. The high-standard measurements are either performed in the laboratory before the instrument is deployed to the field, or in the field if the third standard is permanently installed (Sect. 3.2). The above secondary correction is applied using only two tanks to perform the fit and obtain the driftcorrected sensitivity. In this special case, the fit has zero degrees of freedom with no residuals. The correction parameters (slope and intercept) are determined based on measurements over time or single measurements in the laboratory prior to a specific analyzer deployment. The correction is applied to the data from the site for a time period that is specified, i.e., it is not automatically applied based on daily measurements of the high standard. It is determined by the science team and applied for the time period that is appropriate. This is necessary to avoid applying the wrong correction if an analyzer is replaced or if there are changes made to the analyzer that might affect its calibration response. At eight sites where a high standard has been measured at any point (MSH, BWD, NWB, NEB, JES, TMD, CPH, and HRD), slopes and intercepts have been determined and the correction has been applied to the data. At stations with no high-standard measurements, we rely on the single-tank drift-correction described in Sect. 3.3.

Laboratory tests with multiple standards with the same model instrument used in the network (Picarro 2301) were performed to assess the relative improvement of a fit to two standards over a fit to a single standard. Figure 6a illustrates the fit of the drift-corrected sensitivity $\left(S_{\mathrm{DC}}\right)$ to two standards (red line) vs. all five standards (blue line) for $\mathrm{CO}_{2}$, along with corresponding residuals in Fig. 6b. As was shown by Verhulst et al. (2017) for multiple analyzers, the fit to a single standard has a linearly varying residual that is typically 0.1 to 0.2 at $100 \mu \mathrm{mol} \mathrm{mol}^{-1}$ above the calibration standard value (green circles, Fig. 6b). The average slope of the one-point residual from multiple tests is used by Verhulst et al. (2017) to estimate the uncertainty of the single-point calibrations (called the extrapolation uncertainty, $U_{\text {extrap}}$ ), described in Sect. 4.1. Performing the additional correction using a high standard shows improvement in the residuals of the fit (Fig. 6b), while using all five standards only improves the residuals incrementally. The two-point correction (red) in this figure was applied using the $406 \mu \mathrm{mol} \mathrm{mol}^{-1}$ tank as the calibration and 

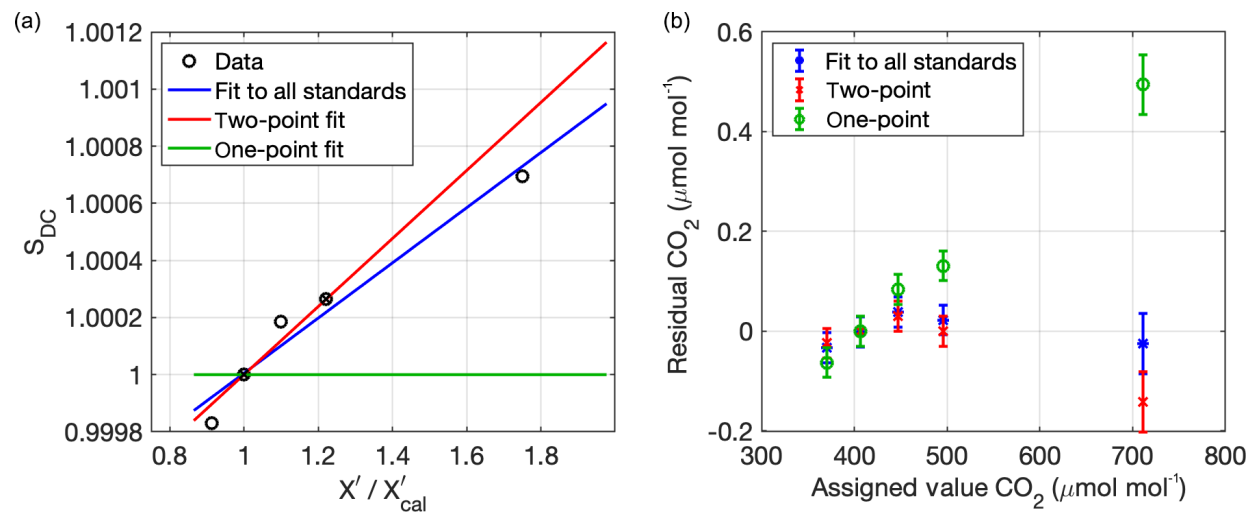

Figure 6. Example of a laboratory calibration of a CRDS analyzer with five standards of different assigned $\mathrm{CO}_{2}$ mole fractions. (a) Secondary correction of drift-corrected sensitivity using either two (red) or all five (blue) standards. Green line at 1 indicates the assumed sensitivity when only a single standard is used. (b) Residual of each type of fit; error bars represent $1 \sigma$ reproducibility stated by NOAA/ESRL. The simple single-tank drift correction results in the green circles as residuals; these residuals were used in the Verhulst et al. (2017) analysis to estimate the extrapolation uncertainty of the single-point correction. Red x symbols are the residuals of a fit to two standards, and blue asterisks are the residuals of the fit to all five standards.

the $496 \mu \mathrm{mol} \mathrm{mol}^{-1}$ tank as the high standard; thus, the measurement at $\sim 711 \mu \mathrm{mol} \mathrm{mol}^{-1}$ is an extrapolation of the twopoint fit. The residuals at values between the calibration and high standard are very small, equal to or below the uncertainty (reproducibility) of the scale reported by NOAA; this was confirmed for other analyzers and other species.

The improvement in calibration from the secondary correction is quite small compared to the signals and gradients of interest in our network. For example, when considering the enhancement between the rural site TMD and a polluted urban site, HRD, the calibration method makes a median difference of $0.4 \%$ for $\mathrm{CO}_{2}$ and $0.3 \%$ for $\mathrm{CH}_{4}$ (over all hours over 1 calendar year). We intend to implement this calibration throughout the network through deployment of additional standards and periodic traveling calibrations when permanent installation is not practical for logistical reasons.

\subsection{Data quality and processing}

Automated data filtering is performed within the GCWerks software with parameters set identically to those extensively described by Verhulst et al. (2017) for the Los Angeles Megacities network. For example, individual measurements that are outside limits for cavity temperature, cavity pressure, and during transitions between sample streams are filtered. The data are automatically downloaded from each site's Linux PC to the central EN Linux server, where they are processed automatically every hour. We note that all mole fraction assignments can be recalculated by the GCWerks software from the archived raw files if required due to a change in filtering or flagging, or in assignment of a standard tank, for example, in the case of a scale change by the CCL. The data files exported from GCWerks contain 1, 5, and $20 \mathrm{~min}$ averaged air data, as well as separate files with 1,5 , and $20 \mathrm{~min}$ averages of all standard runs. Individual or groups of 1 min data points are flagged manually by EN or NIST researchers in the GCWerks if there is cause (e.g., a site visit that disrupted the sample stream or a leak in the line). Some additional quality checking is performed at this stage, specifically checking for systematic differences between measurements from two different inlets at the same height and checking for inconsistencies in the difference between measurements at different heights. For example, if the lower inlet is systematically reading lower $\mathrm{CO}_{2}$ than the upper inlet, especially at night, it would indicate that the inlet lines may be switched (mislabeled) or there is a leak occurring. These indications would be then verified by a field technician, and the data are either reprocessed or flagged accordingly. Filtered and flagged points are excluded from the subsequent averaging exported by GCWerks. The $1 \mathrm{~min}$ air data files and 20 min standard data files are post-processed at NIST to calculate hourly averages from each air inlet level and to assign uncertainties to each hourly average (Sect. 4). Data from the two top-level inlets, when they are at the same height, are combined for inclusion into the hourly average. Thus, because of the $20 \mathrm{~min}$ cycling through the three inlets (Sect. 3.1), hourly averages at the upper inlet include approximately $40 \mathrm{~min}$ of measurements, and for the lower inlet only $20 \mathrm{~min}$ (fewer if a calibration occurs). Publicly released hourly data from this second-level processing are contained in separate files for each species and each level for each site. The files contain the hourly average mole fraction (i.e., mole fraction) along with its uncertainty, standard deviation, and number of $1 \mathrm{~min}$ air measurements included in that particular hourly average. These last two quantities are provided so users can determine the standard error of the hourly means in terms of the observed atmospheric variability within the hour. Observations at higher frequency and standard tank data are available by request. 


\subsection{Comparison with measurements of NOAA whole air samples}

Ongoing whole air sampling in flasks at several of the NEC sites by NOAA Earth System Research Laboratory's Global Monitoring Division (NOAA/GMD) provides a check on the quality of the in situ measurements. The flasks are analyzed for $\mathrm{CO}_{2}, \mathrm{CH}_{4}$, and $\mathrm{CO}$, among a suite of additional trace gases and isotopes that are not discussed here. The flasksampling equipment draws air from one of the inlet lines at the top of the tower that is also shared by the continuous in situ measurement equipment (as indicated by the flask port in Fig. 4). The flask measurements are otherwise independent from the continuous in situ measurements. Flask samples at LEW and MSH are collected over a period of 10-30 s (Sweeney et al., 2015; Andrews et al., 2014), while flask samples integrated over $1 \mathrm{~h}$ are collected at TMD, NEB, NWB, and BWD (Turnbull et al., 2012) specifically as part of the Northeast Corridor project. All flask samples are taken in midafternoon local time (usually 19:00 UTC). Comparisons at all the sites with available data indicate good agreement with little or no bias in the mean over the time period of the comparison, with the exception of $\mathrm{CO}$ at MSH, which shows a consistent bias with a median of $8 \mathrm{nmol} \mathrm{mol}^{-1}$, which is larger than the $1 \sigma$ uncertainty assigned to either measurement (described in Sect. 4) and the standard deviation of the offsets themselves (Table 2). Target tank residuals for $\mathrm{CO}$ in this period range from 1 to $7 \mathrm{nmol} \mathrm{mol}^{-1}$, depending on the cylinders installed, indicating that at least some of this difference is caused by the calibration standard assigned value (possibly due to cylinder drift in time between the NOAA calibration and deployment to the site). Similar differences between NOAA flasks and in situ CO measurements were reported in Indianapolis (Richardson et al., 2017). This result requires further investigation, by sending the cylinders for recalibration and/or deploying different standards to the station. A significant bias in the $\mathrm{CH}_{4}$ offset at NWB is also apparent, at a mean of $-5.5 \mathrm{nmol} \mathrm{mol}^{-1}$ but a median of $-1.7 \mathrm{nmol} \mathrm{mol}^{-1}$, the result of a single outlier at $-30 \mathrm{nmol} \mathrm{mol}^{-1}$ but with only 17 samples compared. BWD did not have any samples at the time of writing, thus we compare only LEW, MSH, TMD, NEB, and NWB.

Table 2 also reports the mean uncertainty, intended as a metric for comparison of the standard deviation of the offsets. For each flask sample, this uncertainty is the quadrature sum of the continuous data uncertainty (described in Sect. 4) at that hour, the standard deviation of the $1 \mathrm{~min}$ averages in the continuous data during that hour, and the uncertainty expected in the flask measurement, estimated here as $0.04 \mu \mathrm{mol} \mathrm{mol}^{-1}$ for $\mathrm{CO}_{2}, 1.12 \mathrm{nmol} \mathrm{mol}^{-1}$ for $\mathrm{CH}_{4}$, and $0.59 \mathrm{nmol} \mathrm{mol}^{-1}$ for $\mathrm{CO}$. The values for the flask uncertainty are from Table 1 in Sweeney et al. (2015), which reports the average offset between measurements of surface network and 12-pack flasks (such as those used for the NEC) filled with identical air after a short-term storage test. For $\mathrm{CO}_{2}$, flask offsets can be larger than indicated by those dry-air laboratory tests (Sweeney et al., 2015; Andrews et al., 2014; Karion et al., 2013), but we use $0.04 \mu \mathrm{mol} \mathrm{mol}^{-1}$ regardless because the average uncertainty in Table 2 is dominated by the atmospheric variability term and increasing the $\mathrm{CO}_{2}$ uncertainty in the flasks to $0.1 \mu \mathrm{mol} \mathrm{mol}^{-1}$ (for example) does not change the values significantly.

Standard deviations of the offsets (Table 2) show that there is quite a bit of scatter in the results, especially at the more urban sites that exhibit a lot of variability in the continuous data. For comparison, Turnbull et al. (2015) report agreement for $\mathrm{CO}_{2}$ between the same flask system and continuous in situ measurements in Indianapolis as $0.04 \mu \mathrm{mol} \mathrm{mol}^{-1}$ (mean) with a standard deviation of $0.38 \mu \mathrm{mol} \mathrm{mol}^{-1}$, somewhat smaller than what was observed at our sites. The standard deviation of offsets is usually lower than the average uncertainty, however, with the exception of $\mathrm{CO}_{2}$ at $\mathrm{MSH}$ and LEW, the two sites for which the flask samples are not integrated over an hour. It is likely that the large variability seen over an hour is the reason for the large scatter in the offsets. Because the continuous in situ measurements do not cover the entire hour of sampling (at the top level, the hourly average is typically the mean of only $40 \mathrm{~min}$ ), the variability may not be captured in the mean uncertainty reported here and has a larger impact on the comparison than it would if the continuous hourly average was based on the full hour of observations. For example, a large plume or spike in concentration during a given hour might occur while the continuous system is sampling from the lower inlet and thus would not be included in the hourly average from the continuous system, while it would be included in the full $1 \mathrm{~h}$ flask sample.

\section{Uncertainty}

The data set includes an uncertainty estimate on each hourly average data point, consistent with recommendations from the WMO (WMO, 2018). This uncertainty is our estimate of the uncertainty of the measurement itself and does not include atmospheric variability or assess the representativeness of the measurement of a true hourly mean.

\subsection{Uncertainty of hourly mole fraction data}

Verhulst et al. (2017) outlined a method for calculating an uncertainty in mole fraction measurements when using the single-tank calibration correction (drift correction). Here we present a brief overview but refer the reader to that paper for further details. All uncertainties are standard uncertainties, i.e., $1 \sigma$ or $k=1$. In the analysis below, we assume independent uncorrelated error components, given no evidence to the contrary and no physical reason to believe that they should be correlated; therefore, we sum the various components of the uncertainty in quadrature.

The uncertainty in the final mole fractions $\left(U_{\text {air }}\right)$ is expressed as the quadrature sum of several uncertainty com- 


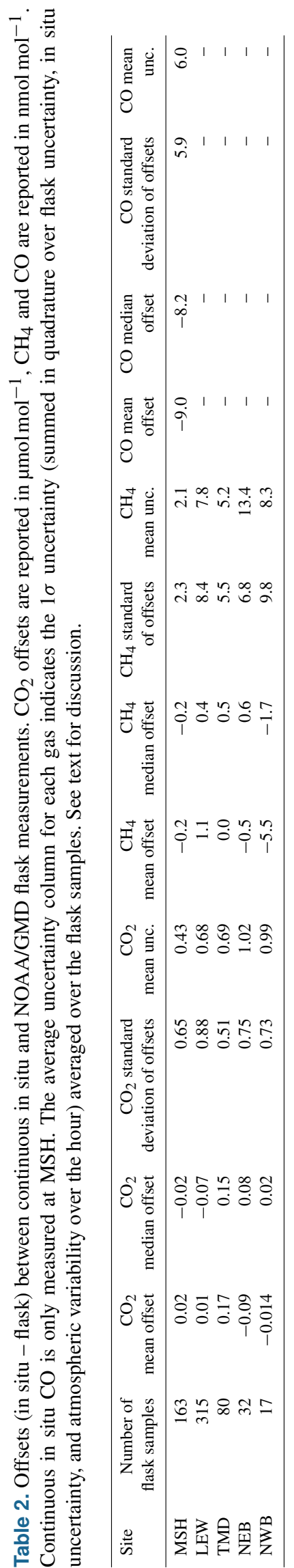

ponents:

$\left(U_{\text {air }}\right)^{2}=\left(U_{\text {extrap }}\right)^{2}+\left(U_{\mathrm{H}_{2} \mathrm{O}}\right)^{2}+\left(U_{\mathrm{M}}\right)^{2}$,

where $U_{\mathrm{H}_{2} \mathrm{O}}$ is the uncertainty due to the water vapor correction, $U_{\mathrm{M}}$ is a measurement uncertainty, and $U_{\text {extrap }}$ is the uncertainty of the calibration fit when assigning values relative to a single standard tank (more detail on this can be found later in this section and in the following section). $U_{\mathrm{M}}$ encompasses errors due to drifting standard tank measurements $\left(U_{\mathrm{b}}\right)$, short-term precision $\left(U_{\mathrm{p}}\right)$, and error in the calibration standard's mole fraction assignment by the calibration laboratory $\left(U_{\text {scale }}\right)$ :

$\left(U_{\mathrm{M}}\right)^{2}=\left(U_{\mathrm{p}}\right)^{2}+\left(U_{\mathrm{b}}\right)^{2}+\left(U_{\text {scale }}\right)^{2}$.

Here we note that $U_{\mathrm{p}}$ for $\mathrm{CO}_{2}$ and $\mathrm{CH}_{4}$ is assigned as described by Verhulst et al. (2017), as the standard deviation of the individual measurements during each $1 \mathrm{~min}$ average during a calibration, but for $\mathrm{CO}$ it is assigned as the standard error (standard deviation divided by the square root of the number of samples in the mean), based on Allan variance tests (not shown) indicating that the precision of the $\mathrm{CO}$ measurement increases with the number of points used in the average. If no calibrations have been performed over an entire calendar year, $U_{\mathrm{p}}$ is set to the 10th percentile of the standard deviation of air measurements and $U_{\mathrm{b}}$ is set to a default value of $0.1 \mu \mathrm{mol} \mathrm{mol}^{-1}, 0.5 \mathrm{nmol} \mathrm{mol}^{-1}$, and $4 \mathrm{nmol} \mathrm{mol}^{-1}$ for $\mathrm{CO}_{2}, \mathrm{CH}_{4}$, and $\mathrm{CO}$, respectively. This default value for $U_{\mathrm{b}}$ is based on an upper limit of values that are observed in the network; typically, $U_{\mathrm{b}}$ is much smaller than these values (Verhulst et al., 2017). In the current data set, this has only occurred once: there were no calibrations run at MNC over the entire 2015 calendar year, but we have no knowledge of abnormal operations or changes during this period, with analyzer sensitivity being similar before and after this period.

Because these uncertainty components are also tested through the use of a target tank, or check standard, the uncertainty $U_{\mathrm{M}}$ is assigned as the root mean square of the target tank errors when those exceed the sum of the uncertainties above.

$U_{\mathrm{M}}=U_{\mathrm{TGT}}=\sqrt{\frac{\sum\left(\left(X_{\mathrm{DC}, \mathrm{TGT}}-C_{\mathrm{TGT}}\right)^{2}\right)}{N}}$

This residual is calculated by GCWerks, and the root-meansquare residual is interpolated in time as a moving $10 \mathrm{~d}$ average. If a target tank has not been run through the system for $10 \mathrm{~d}$ or longer, $U_{\mathrm{TGT}}$ is set to a default value that is currently set to $0.2 \mu \mathrm{mol} \mathrm{mol}^{-1}, 1 \mathrm{nmol} \mathrm{mol}^{-1}$, and $6 \mathrm{nmol} \mathrm{mol}^{-1}$ for $\mathrm{CO}_{2}, \mathrm{CH}_{4}$, and $\mathrm{CO}$, respectively, based on typical maximum values for this uncertainty calculated from many sites over several years. The target tank in the field generally has a concentration value very similar to the calibration tank, thus this residual is a good estimate of the uncertainty caused by 
the precision, baseline changes, and tank value assignment. However, it is not a good indicator of uncertainty at mole fractions different from that of the calibration tank. Therefore, we assign an added uncertainty component, $U_{\text {extrap, in- }}$ dicating the uncertainty that increases as the measurement value moves farther from the value of the calibration tank in the case of a single calibration standard. This was found to be a linear relationship for a series of similar model analyzers that were tested in a laboratory, and the uncertainty was described as follows:

$U_{\text {extrap }}=|\varepsilon|\left|X_{\mathrm{DC}, \text { air }}-C_{\text {cal }}\right|$.

See Verhulst et al. (2017) for details on determining the unitless slope of the uncertainty, epsilon $(\varepsilon)$, which is currently assigned as $0.0025,0.0031$, and 0.0164 for $\mathrm{CO}_{2}, \mathrm{CH}_{4}$, and $\mathrm{CO}$, respectively, for all data that are only drift corrected (i.e., not using a high standard).

\subsection{Uncertainty for observations with additional standards available}

When a high-standard tank is available and the secondary correction described in Sect. 3.4 is applied, the uncertainty analysis remains similar, but the uncertainty $U_{\text {extrap from }}$ Eqs. (7) and (10) is replaced by an uncertainty in the twopoint fit, $U_{\text {fit }}$. To estimate this uncertainty for $\mathrm{CO}_{2}$ and $\mathrm{CH}_{4}$, we use the reported uncertainty of the assigned value of the high-standard and calibration-standard tanks, $U_{\text {scale, }}$ (typically $0.03 \mu \mathrm{mol} \mathrm{mol}^{-1} \mathrm{CO}_{2}$ and $0.5 \mathrm{nmol} \mathrm{mol}^{-1} \mathrm{CH}_{4}$ at $1 \sigma$ ) along with an estimate of the precision of the analyzer, $U_{\mathrm{p}}$, to estimate an uncertainty in the drift-corrected sensitivity of the high standard, $U_{\mathrm{SDC} \text {,hstd }}$, using standard propagation of errors (black error bar, Fig. 7a). We note that in the case where the value assigned to the high standard is through a propagation of the WMO scale at NIST, the assigned value has additional uncertainty; i.e., $U_{\text {scale }}$ includes both the uncertainty that NOAA assigned to the cylinders used for the assignment and the uncertainty from the laboratory fit at NIST. This second uncertainty is equal to the standard deviation of the residuals of the fit and is added in quadrature to the NOAA uncertainty.

We note that the analysis described below assumes uncorrelated independent errors. We express the slope of driftcorrected sensitivity $(m)$ and the overall drift-corrected sensitivity $\left(S_{\mathrm{DC}}\right)$ as functions only of the drift-corrected sensitivity of the high standard, $S_{\mathrm{DC} \text {,hstd }}$ :

$$
\begin{aligned}
& m=\frac{S_{\mathrm{DC}, \mathrm{hstd}}-1}{X_{\mathrm{hstd}}^{\prime} / X_{\mathrm{cal}}^{\prime}-1} \\
& S_{\mathrm{DC}}=m\left(\frac{X^{\prime}}{X_{\mathrm{cal}}^{\prime}}-1\right)+1 .
\end{aligned}
$$

This second equation uses $b=1-m$. Here we do not include uncertainty in the $x$ coordinate, i.e., $X^{\prime} / X_{\text {cal }}^{\prime}$. Uncertainty in the slope is as follows:

$U_{m}=\left|\left(\frac{U_{\mathrm{SDC}, \mathrm{hstd}}}{\left(X_{\mathrm{hstd}}^{\prime} / X_{\text {cal }}^{\prime}\right)-1}\right)\right|$.

We propagate the uncertainty in the drift-corrected sensitivity of the high standard, $U_{\mathrm{SDC} \text {,hstd }}$, to the overall drift-corrected sensitivity of all the air values using Eq. (14) and then to the two-point corrected air data by propagating through to obtain Eq. (15).

$$
\begin{aligned}
& U_{\mathrm{SDC}}=U_{m}\left(X^{\prime} / X^{\prime} \text { cal }-1\right) \\
& =\left|\left(\frac{U_{\mathrm{SDC}, \mathrm{hstd}}}{\left(X_{\mathrm{hstd}}^{\prime} / X^{\prime}{ }_{\mathrm{cal}}\right)-1}\right)\left(X^{\prime} / X^{\prime}{ }_{\mathrm{cal}}-1\right)\right| \\
& U_{\mathrm{XSC}, \text { air }}=U_{\mathrm{fit}}=\left|\frac{U_{\mathrm{SDC}}}{S_{\mathrm{DC}}}\right| X_{\mathrm{SC}, \text { air }}
\end{aligned}
$$

To evaluate the use of standard propagation of errors, we also use a bootstrap to estimate the uncertainty using the laboratory calibration shown in Fig. 6 by randomly selecting two tanks of the five tanks from the test to calculate 1000 versions of the correction (blue shading shows the standard deviation of the result, Fig. 7). For this test, the calculated $1 \sigma$ uncertainty (red shading) was similar to the $1 \sigma$ bootstrap uncertainty (slightly larger for $\mathrm{CO}_{2}$ and slightly smaller for $\mathrm{CH}_{4}$, not shown). This comparison indicates that the estimated uncertainty using the equations above compares reasonably well with the uncertainty we would derive from a bootstrap analysis, which gives us confidence in our methodology.

The uncertainty in $S_{\mathrm{DC}}$ leads to the estimate of the fit uncertainty, $U_{\text {fit }}$, shown in Fig. 7b. To implement this uncertainty across all times and towers, we calculate it assuming a fixed nominal value of the high calibration standard of $490.50 \mu \mathrm{mol} \mathrm{mol}^{-1} \mathrm{CO}_{2}$ and $2560.61 \mathrm{nmol} \mathrm{mol}^{-1} \mathrm{CH}_{4}$. This is based on the value of the high standard that was in residence in the Earth Networks laboratory when several of the CRDS analyzers were tested and assigned two-point calibration corrections. We use the site-specific (instrument-specific and period-specific) slope and intercept that are applied to the data (which are static over the time period they are applied) and the value of the calibration tank to calculate the remainder of the values required for the uncertainty analysis.

Only one site so far, MSH, measures continuous $\mathrm{CO}$, and the history of standard tanks there indicates significant uncertainty in tank value assignments with large target tank residuals and corresponding $U_{\mathrm{TGT}}$ relative to errors in slope. We have chosen not to implement the two-point calibration at this site for $\mathrm{CO}$ because the range of slopes of $S_{\mathrm{DC}}$ includes one, i.e., the correction is so small that the uncertainty dwarfs the correction.

Mean absolute residuals of the two-point fit for nine laboratory calibrations analyzed (seven tested at NOAA/ESRL and described by Verhulst et al., 2017, Table S2, and two additional units at NIST) average to $0.03 \mu \mathrm{mol} \mathrm{mol}^{-1}$ for $\mathrm{CO}_{2}$ 

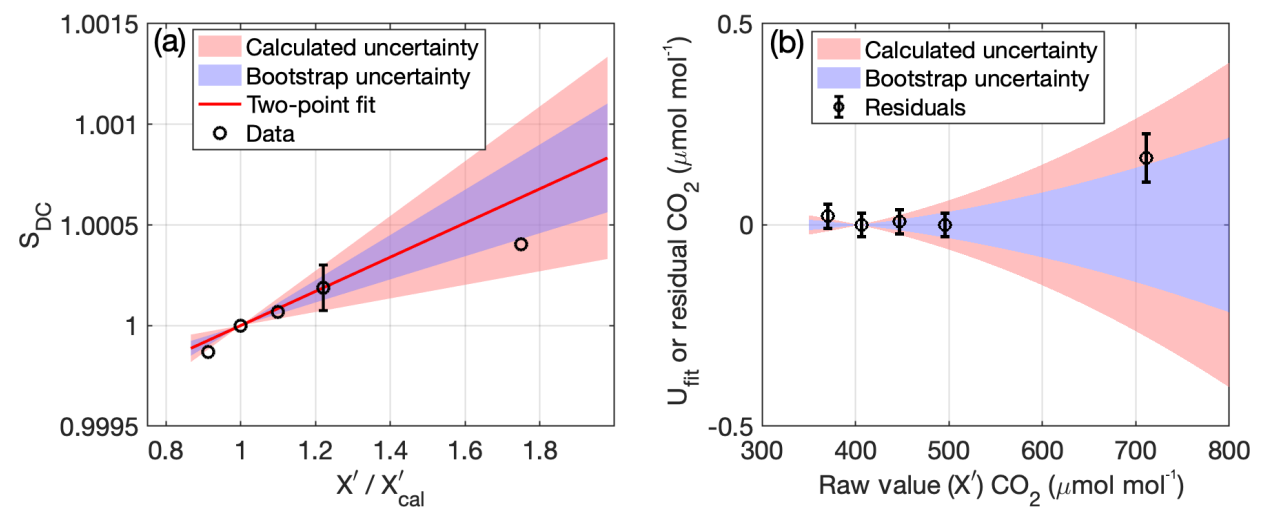

Figure 7. Uncertainty $(1 \sigma)$ in fit for two-point calibrations. (a) Two-point fit to drift-corrected sensitivity $\left(S_{\mathrm{DC}}\right)$ (red line) with uncertainty (red shading) calculated using the uncertainty in the high standard (black circle with error bar). Blue shading shows uncertainty calculated using a bootstrap conducted by randomly selecting sets of two standards from the laboratory test (black circles) to calculate the slope. There is no uncertainty at 1 because the drift-corrected sensitivity is defined as equal to one at the value of the calibration standard. (b) Uncertainty in final $\mathrm{CO}_{2}$ as a function of raw $\mathrm{CO}_{2}$; red and blue shading have the same meaning as in (a).

between the calibration and high-standard data, and larger for the test that included an even higher-concentration tank, shown in Fig. 7 at $\sim 711 \mu \mathrm{mol} \mathrm{mol}^{-1}$ for $\mathrm{CO}_{2}$. The fit uncertainty encompasses (at $1 \sigma$ ) this residual as well (Fig. 7b). The residuals at lower values can be explained by the uncertainty in the measurement (precision) and uncertainty in value assignment of the tanks. For CO, only eight tests were available, with a mean residual inside the range of the calibrations of $1.1 \mathrm{nmol} \mathrm{mol}^{-1}$, higher than the reported reproducibility from NOAA of $0.4 \mathrm{nmol} \mathrm{mol}^{-1}$ (all values are noted here at $1 \sigma$ although they are given by NOAA at $2 \sigma$ ). This larger residual is likely caused by the lower precision of the analyzers for $\mathrm{CO}$ but also could be caused by larger uncertainty in the tank assignments, possibly due to drift in the mole fraction of the tanks themselves. We intend to conduct additional tests outside the two-point calibration range with additional analyzers and tanks to evaluate and possibly update this uncertainty component, $U_{\text {fit }}$, as needed, and especially focus on $\mathrm{CO}$ if and when additional $\mathrm{CO}$ measurements are added to our network.

\section{Network observations}

Here we show some observations and time series of $\mathrm{CO}_{2}$ and $\mathrm{CH}_{4}$ from the NEC in situ tower network, focusing on data coverage, vertical gradients, and observed differences between urban and rural or outer suburban sites.

\subsection{Data coverage and network expansion}

The NEC network is continuously growing, with sites coming online at different times. Figure 8 shows the availability of hourly observations as the various sites have come online.

\subsection{Vertical gradients}

Observations in global trace gas measurement networks (e.g., AGAGE, GGRN) are specifically sited far from local sources or strong sinks to ensure that air reaching the site is representative of the large spatial scales of interest to a global study. This allows the observations to be more easily interpreted by a coarser global model (e.g., Peters et al., 2007). In urban networks, it is desirable to measure trace gas concentrations closer to sources so that finer spatial gradients can be used to inform emissions estimates at urban scales. However, a balance must be struck between the necessity to observe and distinguish sources that are in close proximity to each other and the ability of a transport and dispersion model to simulate the observations. In some instances, novel ways to simulate observations at low heights above ground level and in very dense networks have been used to resolve this problem (Berchet et al., 2017). In the NEC urban network in Washington, DC, and Baltimore, the tower sites were selected to be between 50 and $100 \mathrm{~m}$ above the ground given the desire to place a tower in a specific location (as identified in an initial network design study by Lopez-Coto et al., 2017). Inlets at two (or three, at SFD) heights on the tower give some insight as to the proximity of each tower to sources whose emissions are not always vertically well mixed by the time they reach the inlets, depending on atmospheric stability conditions. Here we report average vertical gradients, determined using the observations at different levels, for the urban and background sites in our network. These gradients were calculated using hourly average data from each level, but because the instruments are only sampling from one level at any given time and cycling between them, there is an assumption of measurements averaged in a given hour being representative of the entire hour. Because different towers have different inlet heights and different vertical spacing between the lower and upper inlet, here we compare three urban sites (ARL, 


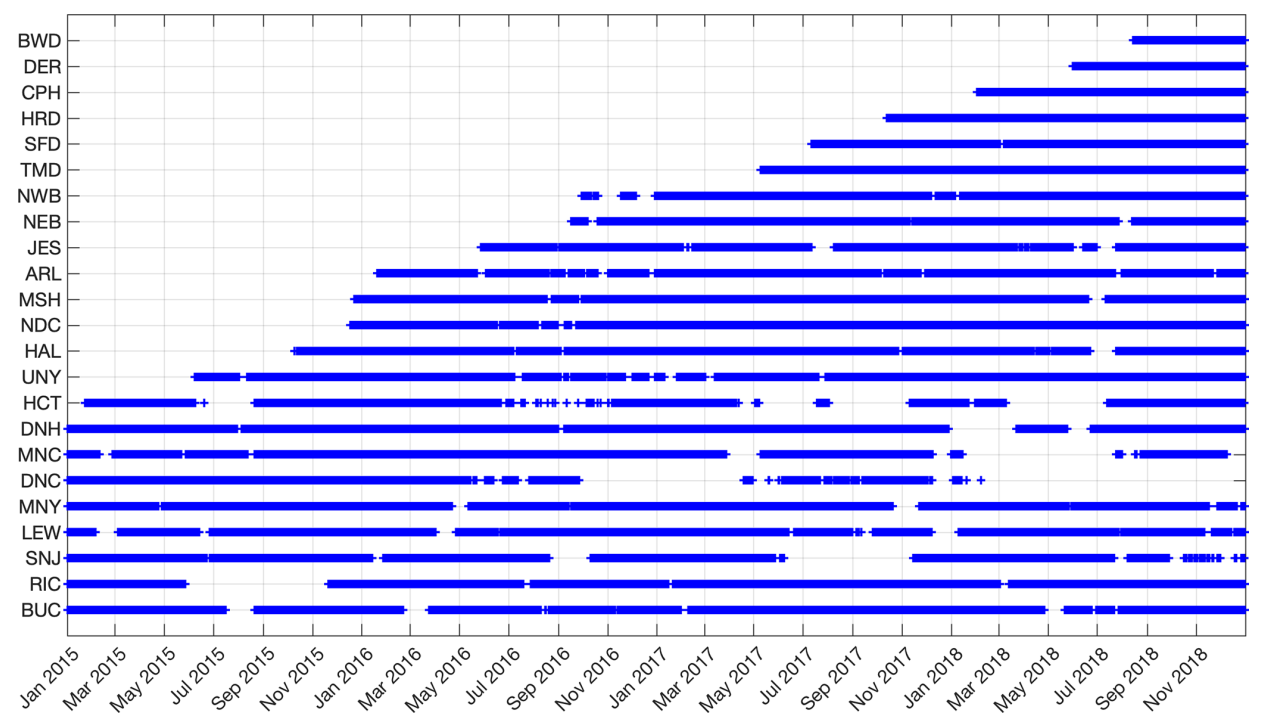

Figure 8. Data $\left(\mathrm{CO}_{2}\right.$ and $\mathrm{CH}_{4}$, and $\mathrm{CO}$ for $\mathrm{MSH}$ only) availability from the various NIST-EN tower sites in the Northeast Corridor network included in this data release. Gaps represent data outages due to various failures (analyzer, communications, etc.).

NDC, and JES) with inlets at similar heights, $\sim 90 \mathrm{~m}$ and $\sim 50 \mathrm{~m}$ a.g.l. We define the gradient as the mole fraction of $\mathrm{CO}_{2}$ or $\mathrm{CH}_{4}$ at the topmost inlet minus that of the lowermost inlet divided by the distance between them so that a negative gradient indicates a higher concentration at the lower inlet (the most common case).

Analysis of the diurnal cycle of the vertical gradient at urban sites in the Washington-Baltimore area (Fig. 9) indicates different characteristics in summer vs. winter. These differences are most likely caused by different meteorology and possible seasonal differences in timing of fluxes, especially for sites influenced by the urban biosphere. Greater turbulent mixing in summertime boundary layers and different timing in the boundary layer growth and collapse mostly dominate the seasonal differences. This analysis shows that at these three sites the wintertime average gradient in midafternoon hours (defined based on these figures as 11:00-16:00 LST) is approximately $-0.016 \mu \mathrm{mol} \mathrm{mol}^{-1}$ $\mathrm{m}^{-1}$ for $\mathrm{CO}_{2}\left(-0.105 \mathrm{nmol} \mathrm{mol}^{-1} \mathrm{~m}^{-1}\right.$ for $\left.\mathrm{CH}_{4}\right)$, which translates to a $-0.8 \mu \mathrm{mol} \mathrm{mol}^{-1}\left(-5.2 \mathrm{nmol} \mathrm{mol}^{-1}\right.$ for $\left.\mathrm{CH}_{4}\right)$ difference between levels spaced $50 \mathrm{~m}$ apart; this is not an insignificant gradient. At other urban sites with shorter towers, they can be even larger. These observations can help evaluate vertical mixing in transport and dispersion models that might be used to estimate emissions, or to identify times when modeled and observed vertical gradients agree. Large vertical gradients overnight into the early morning at all sites and seasons are indicative of local sources (likely mostly anthropogenic but also including respiration from the biosphere) influencing the observations at these times when there is stable stratification in the boundary layer and concentrations are higher near the surface. The larger $\mathrm{CO}_{2}$ gradients overnight in summer compared to winter periods suggest a strong res- piration signal at these urban sites, with a large degree of variability between sites indicated by large spread. Nighttime $\mathrm{CH}_{4}$ gradients are slightly larger in winter than summer, possibly reflecting greater wintertime anthropogenic $\mathrm{CH}_{4}$ emissions, or possibly due to seasonality in mixing layer heights.

The diurnal cycle of the vertical gradients from the sites identified as background stations for the WashingtonBaltimore urban network shows large variability in summertime gradients between the three stations (Fig. 10). Stafford, VA (SFD), shows that the surrounding biosphere causes relatively large gradients in nighttime and early morning hours at this low-density suburban site. These are apparent at Bucktown, MD (BUC), as well but less so at Thurmont, MD (TMD), a forested site in western Maryland. The large difference between summertime early morning vertical $\mathrm{CO}_{2}$ gradients at SFD and TMD, despite the similar surrounding land use (mostly deciduous forest, Fig. 3), might be caused by the elevation difference, as SFD is close to sea level while TMD is on a ridge at $561 \mathrm{~m}$ elevation. BUC observations show larger $\mathrm{CH}_{4}$ gradients in summer, due to surrounding wetlands and agriculture (Fig. 3). Wintertime gradients are near zero at all hours at all three of these sites, indicating that they are far from local anthropogenic sources of either gas. We note that the top inlet height at BUC is lower, at $75 \mathrm{~m}$, than at SFD or TMD (100 and $111 \mathrm{~m})$, while the lower inlet is similar for all three $(\sim 50 \mathrm{~m})$. For SFD (inlets at 152, 100, and $50 \mathrm{~m}$ ), we use the 100 and $50 \mathrm{~m}$ inlets to define the gradient to be more consistent with the inlet heights of the other towers (Table 1). 

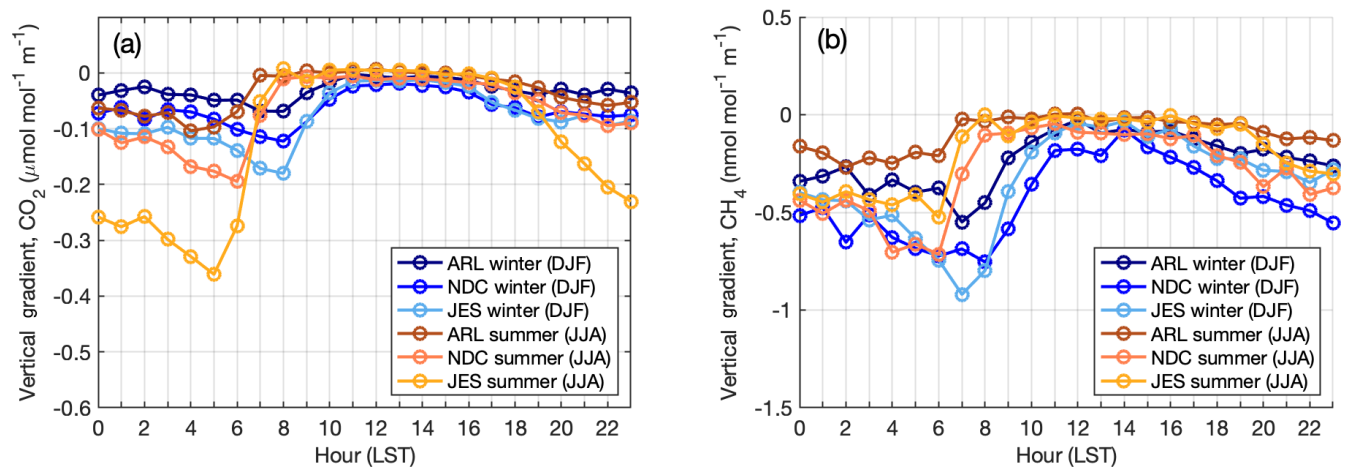

Figure 9. Diurnal cycle of vertical gradients in $\mathrm{CO}_{2}$ (a) and $\mathrm{CH}_{4}$ (b) for urban towers in the Washington-Baltimore area, averaged over 2015-2017 in winter (blue) and summer (orange), with shading indicating $1 \sigma$ standard deviation among sites. Some of the spread can be caused by sampling in different years at the different sites. Sites included are HAL, ARL, NDC, NEB, NWB, and JES. HRD was excluded due to lack of data in this period.
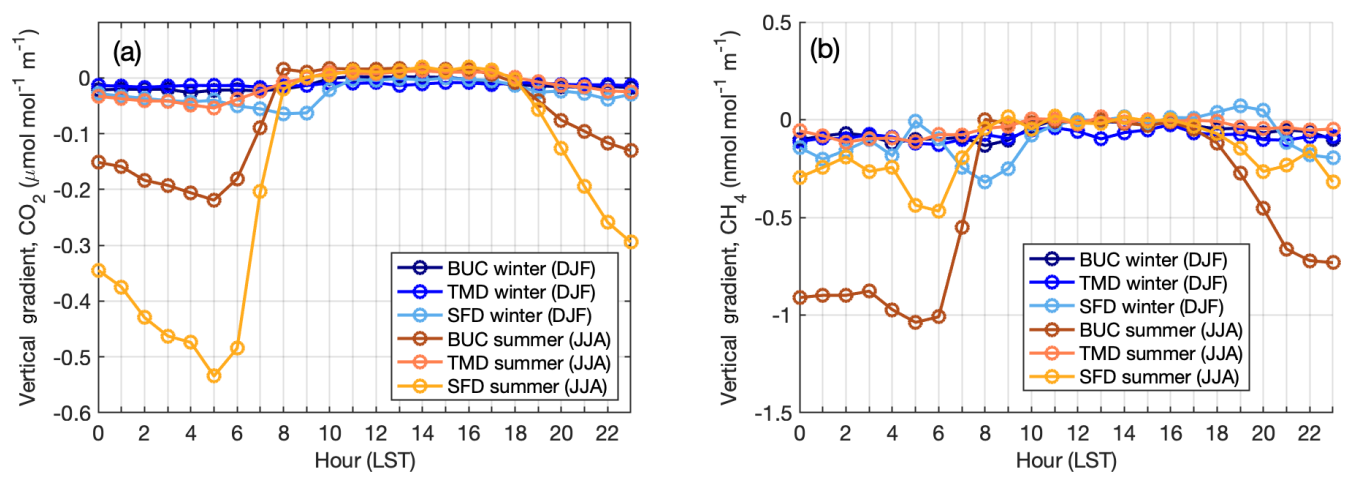

Figure 10. Diurnal cycle of vertical gradients in $\mathrm{CO}_{2}(\mathbf{a})$ and $\mathrm{CH}_{4}(\mathbf{b})$ at the three background towers for the Washington-Baltimore region in summer (orange shades) and winter (blue shades).

\subsection{Urban and rural differences in seasonal cycles}

Here we continue to describe the network in terms of differences between rural (background) and urban stations, determining typical enhancements from urban influences. The seasonal cycles of $\mathrm{CO}_{2}$ and $\mathrm{CH}_{4}$ indicate enhancements in the urban sites in our network relative to the more rural stations throughout the year (Fig. 11). Summertime $\mathrm{CH}_{4}$ at urban sites is not as enhanced compared to the rural sites as it is in winter, possibly due to wetland sources influencing the background station at BUC or lower $\mathrm{CH}_{4}$ emissions from natural gas in urban areas. Similarly, for $\mathrm{CO}_{2}$, some of the rural stations surrounded by active vegetation (Fig. 3) are likely to show stronger influence from biospheric uptake than urban sites, especially in the summer months (Fig. 10). We specifically caution against using any of the in situ data from the NEC rural stations directly as a background for analysis of the urban enhancement without examining these issues. Sargent et al. (2018) indicate that for an analysis of $\mathrm{CO}_{2}$ enhancements in the Boston urban area, $\mathrm{CO}_{2}$ observations from upwind stations alone did not represent the correct background. Even when the air that reaches an urban tower originates near an upwind rural site, back trajectories (from a Lagrangian Particle Dispersion Model such as STILT, for example) indicate that much of the air may originate from a higher altitude than the upwind station. Thus, the measurement at an upwind station is not necessarily representative of the proper background or incoming concentration, given the large concentration gradients between measurements within the planetary boundary layer and in the free troposphere near background stations with local fluxes. Mueller et al. (2018) conducted an analysis of the issues concerning background determination for this urban network, mostly concerning the large emissions of both $\mathrm{CO}_{2}$ and $\mathrm{CH}_{4}$ upwind of the region that is difficult to capture at upwind stations. We will examine the proper background for investigating urban enhancements in the Washington, DC, and Baltimore, MD, area further in future work.

\section{Data availability}

This data set of hourly averaged observations from the Northeast Corridor tower-based network is available on the NIST data portal at https://data.nist.gov (last access: 

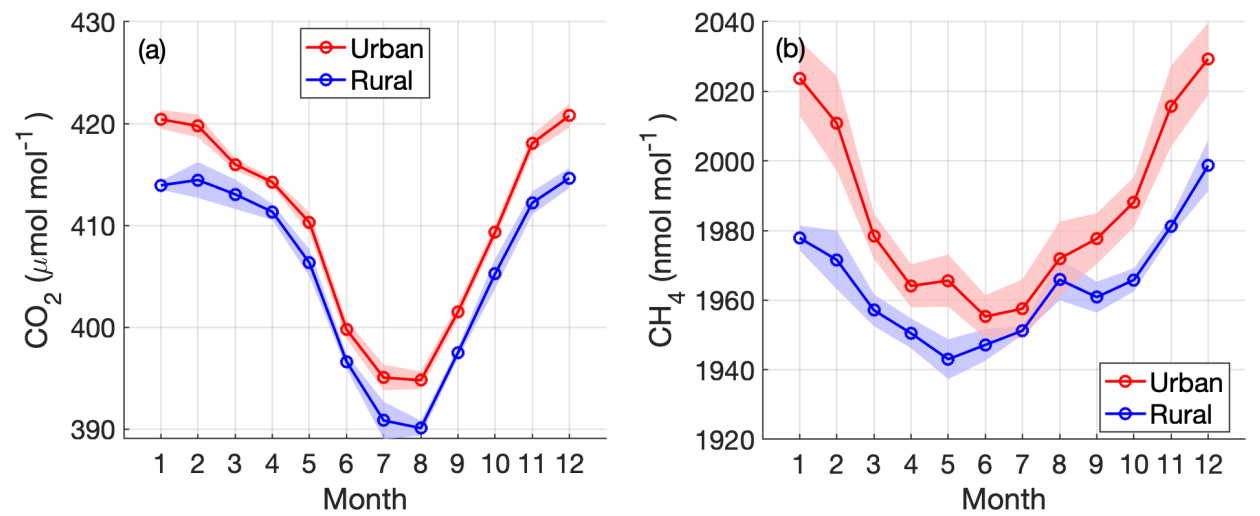

Figure 11. Seasonal cycles from urban and rural sites in the Washington, DC, and Baltimore region with at least 1 year of observations. Midafternoon (13:00-18:00 LST) daily averages are detrended using a linear fit to the annual trend at Mauna Loa (for $\left.\mathrm{CO}_{2}\right)$ and the global average (for $\mathrm{CH}_{4}$ ) (data from NOAA/ESRL) and then averaged monthly. Rural sites include TMD, SFD, and BUC; urban sites are ARL, NDC, JES, HAL, NEB, and NWB. Shading indicates 1 standard deviation of the averages from all the sites.

23 March 2020) under the https://doi.org/10.18434/M32126 (Karion et al., 2019). Initially, the repository will contain data from 23 sites (Table 1) for years spanning 2015-2018; not all years are available for all sites. Files are version-dated, and the current plan is to provide annual updates for 2019 and beyond.

\section{Conclusions}

Here we present a data set of hourly average observations of $\mathrm{CO}_{2}, \mathrm{CH}_{4}$, and $\mathrm{CO}$ (where applicable) from a network of towers in the northeastern United States. Measurements are funded by NIST and conducted in a collaboration with Earth Networks, Inc., with quality control, assurance, and uncertainty determination conducted by a science team that includes NIST, Earth Networks, and collaborators from the Los Angeles Megacities Carbon Project from NASA/JPL and the Scripps Institution of Oceanography. We present 4 calendar years of data (2015 through 2018), with different stations coming online through the years, and most Washington, DC, and Baltimore, MD, urban stations becoming established after late 2015. We have also presented our methodology for calibrating the measurements to WMO scales for each gas and determining uncertainties for these measurements, as recommended by the WMO (WMO, 2018). We show that analysis of observations at two different inlet heights can be useful for determining the presence of emissions close to the towers, which may be necessary for evaluating the efficacy and choice of transport model used to analyze the data. We also note that the tower stations that were established to characterize incoming or background air are not necessarily appropriate for use directly as background for the urban stations, as they are often affected by local fluxes that do not influence the urban stations. A more careful treatment of incoming background air is necessary for any given analysis.
Author contributions. WC, MS, SP, and PS collected data; AK, $\mathrm{KRV}$, JK, and PS performed quality control and data processing and devised the uncertainty analysis. AK implemented the uncertainty analysis and wrote the manuscript, with contributions from SP, JK, ILC, and JW.

Competing interests. The authors declare that they have no conflict of interest.

Acknowledgements. We acknowledge the Earth Networks engineering and technical team, including Uran Veseshta, Clayton Fain, Bryan Biggs, Seth Baldelli, Joe Considine, and Charlie Draper. We also thank Tamae Wong, Kimberly Mueller, Sharon Gourdji, Subhomoy Ghosh, and Antonio Possolo (NIST) for helpful discussions.

Financial support. This work was funded by the NIST Greenhouse Gas Measurements Program.

Review statement. This paper was edited by Alexander Kokhanovsky and reviewed by three anonymous referees.

\section{References}

Andrews, A. E., Kofler, J. D., Trudeau, M. E., Williams, J. C., Neff, D. H., Masarie, K. A., Chao, D. Y., Kitzis, D. R., Novelli, P. C., Zhao, C. L., Dlugokencky, E. J., Lang, P. M., Crotwell, M. J., Fischer, M. L., Parker, M. J., Lee, J. T., Baumann, D. D., Desai, A. R., Stanier, C. O., De Wekker, S. F. J., Wolfe, D. E., Munger, J. W., and Tans, P. P.: $\mathrm{CO}_{2}, \mathrm{CO}$, and $\mathrm{CH}_{4}$ measurements from tall towers in the NOAA Earth System Research Laboratory's Global Greenhouse Gas Reference Network: instrumentation, uncertainty analysis, and recommendations for future high-accuracy greenhouse gas monitoring efforts, Atmos. Meas. Tech., 7, 647687, https://doi.org/10.5194/amt-7-647-2014, 2014. 
Bares, R., Mitchell, L., Fasoli, B., Bowling, D. R., Catharine, D., Garcia, M., Eng, B., Ehleringer, J., and Lin, J. C.: The Utah urban carbon dioxide (UUCON) and Uintah Basin greenhouse gas networks: instrumentation, data, and measurement uncertainty, Earth Syst. Sci. Data, 11, 1291-1308, https://doi.org/10.5194/essd-11-1291-2019, 2019.

Berchet, A., Zink, K., Muller, C., Oettl, D., Brunner, J., Emmenegger, L., and Brunner, D.: A cost-effective method for simulating city-wide air flow and pollutant dispersion at building resolving scale, Atmos. Environ., 158, 181-196, https://doi.org/10.1016/j.atmosenv.2017.03.030, 2017.

Bureau International des Poids et Mesures: The International System of Units (SI), 9th Edn., edited by: BIPM, BI PM, Pavillon de breteuil, 92312 Sevres Cedex, France, 2019.

Chen, H., Winderlich, J., Gerbig, C., Hoefer, A., Rella, C. W., Crosson, E. R., Van Pelt, A. D., Steinbach, J., Kolle, O., Beck, V., Daube, B. C., Gottlieb, E. W., Chow, V. Y., Santoni, G. W., and Wofsy, S. C.: High-accuracy continuous airborne measurements of greenhouse gases $\left(\mathrm{CO}_{2}\right.$ and $\left.\mathrm{CH}_{4}\right)$ using the cavity ringdown spectroscopy (CRDS) technique, Atmos. Meas. Tech., 3, 375-386, https://doi.org/10.5194/amt-3-375-2010, 2010.

Dlugokencky, E. J., Myers, R. C., Lang, P. M., Masarie, K. A., Crotwell, A. M., Thoning, K. W., Hall, B. D., Elkins, J. W., and Steele, L. P.: Conversion of NOAA atmospheric dry air $\mathrm{CH}_{4}$ mole fractions to a gravimetrically prepared standard scale, J. Geophys. Res.-Atmos., 110, D18306, https://doi.org/10.1029/2005JD006035, 2005.

Edenhofer, O., Pichs-Madruga, R., Sokona, Y., Kadner, S., Minx, J. C., Brunner, S., Agrawala, S., Baiocchi, G., Bashmakov, I. A., Blanco, G., Broome, J., Bruckner, T., M. Bustamante, Clarke, L., Grand, M. C., Creutzig, F., Cruz-Núñez, X., Dhakal, S., Dubash, N. K., Eickemeier, P., Farahani, E., Fischedick, M., Fleurbaey, M., Gerlagh, R., Gómez-Echeverri, L., Gupta, S., Harnisch, J., Jiang, K., Jotzo, F., Kartha, S., Klasen, S., Kolstad, C., Krey, V., Kunreuther, H., Lucon, O., Masera, O., Mulugetta, Y., Norgaard, R. B., Patt, A., Ravindranath, N. H., Riahi, K., Roy, J., Sagar, A., Schaeffer, R., Schlömer, S., Seto, K. C., Seyboth, K., Sims, R., Smith, P., Somanathan, E., Stavins, R., Stechow, C. v., Sterner, T., Sugiyama, T., Suh, S., Ürge-Vorsatz, D., Urama, K., Venables, A., Victor, D. G., Weber, E., Zhou, D., Zou, J., and Zwickel, T.: Technical Summary, in: Climate Change 2014: Mitigation of Climate Change: Contribution of Working Group III Contribution to the IPCC Fifth Assessment Report, edited by: Intergovernmental Panel on Climate Change, Cambridge University Press, Cambridge, 2014.

Gurney, K. R., Razlivanov, I., Song, Y., Zhou, Y. Y., Benes, B., and Abdul-Massih, M.: Quantification of Fossil Fuel $\mathrm{CO}_{2}$ Emissions on the Building/Street Scale for a Large US City, Environ. Sci. Technol., 46, 12194-12202, https://doi.org/10.1021/es3011282, 2012.

Gurney, K. R., Liang, J., O’Keeffe, D., Patarasuk, R., Hutchins, M., Huang, J., Rao, P., and Song, Y.: Comparison of Global Downscaled Versus Bottom-Up Fossil Fuel $\mathrm{CO}_{2}$ Emissions at the Urban Scale in Four U.S. Urban Areas, J. Geophys. Res.-Atmos., 124, 2823-2840, https://doi.org/10.1029/2018jd028859, 2019.

Hedelius, J. K., Liu, J., Oda, T., Maksyutov, S., Roehl, C. M., Iraci, L. T., Podolske, J. R., Hillyard, P. W., Liang, J., Gurney, K. R., Wunch, D., and Wennberg, P. O.: Southern California megacity $\mathrm{CO}_{2}, \mathrm{CH}_{4}$, and $\mathrm{CO}$ flux estimates using ground- and space- based remote sensing and a Lagrangian model, Atmos. Chem. Phys., 18, 16271-16291, https://doi.org/10.5194/acp-18-162712018, 2018.

Huang, Y., Kort, E. A., Gourdji, S., Karion, A., Mueller, K., and Ware, J.: Seasonally Resolved Excess Urban Methane Emissions from the Baltimore/Washington, DC Metropoli$\tan$ Region, Environ. Sci. Technol., 53, 11285-11293, https://doi.org/10.1021/acs.est.9b02782, 2019.

Karion, A., Sweeney, C., Wolter, S., Newberger, T., Chen, H., Andrews, A., Kofler, J., Neff, D., and Tans, P.: Long-term greenhouse gas measurements from aircraft, Atmos. Meas. Tech., 6, 511-526, https://doi.org/10.5194/amt-6-511-2013, 2013.

Karion, A., Whetstone, J. R., and Callahan, W.: Observations of $\mathrm{CO}_{2}, \mathrm{CH}_{4}$, and $\mathrm{CO}$ mole fractions from the NIST Northeast Corridor urban testbed, https://doi.org/10.18434/M32126, 2019.

Lamb, B. K., Cambaliza, M. O. L., Davis, K. J., Edburg, S. L., Ferrara, T. W., Floerchinger, C., Heimburger, A. M. E., Herndon, S., Lauvaux, T., Lavoie, T., Lyon, D. R., Miles, N., Prasad, K. R., Richardson, S., Roscioli, J. R., Salmon, O. E., Shepson, P. B., Stirm, B. H., and Whetstone, J.: Direct and Indirect Measurements and Modeling of Methane Emissions in Indianapolis, Indiana, Environ. Sci. Technol., 50, 8910-8530, https://doi.org/10.1021/acs.est.6b01198, 2016.

Lauvaux, T., Miles, N. L., Deng, A. J., Richardson, S. J., Cambaliza, M. O., Davis, K. J., Gaudet, B., Gurney, K. R., Huang, J. H., O’Keefe, D., Song, Y., Karion, A., Oda, T., Patarasuk, R., Razlivanov, I., Sarmiento, D., Shepson, P., Sweeney, C., Turnbull, J., and Wu, K.: High-resolution atmospheric inversion of urban $\mathrm{CO}_{2}$ emissions during the dormant season of the Indianapolis Flux Experiment (INFLUX), J. Geophys. Res.-Atmos., 121, 5213-5236, https://doi.org/10.1002/2015jd024473, 2016.

Lin, J. C., Gerbig, C., Wofsy, S. C., Andrews, A. E., Daube, B. C., Davis, K. J., and Grainger, C. A.: A near-field tool for simulating the upstream influence of atmospheric observations: The Stochastic Time-Inverted Lagrangian Transport (STILT) model, J. Geophys. Res.-Atmos., 108, 4493, https://doi.org/10.1029/2002JD003161, 2003.

Lopez-Coto, I., Ghosh, S., Prasad, K., and Whetstone, J.: Tower-based greenhouse gas measurement network design The National Institute of Standards and Technology North East Corridor Testbed, Adv. Atmos. Sci., 34, 1095-1105, https://doi.org/10.1007/s00376-017-6094-6, 2017.

Lopez-Coto, I., Ren, X., Salmon, O. E., Karion, A., Shepson, P. B., Dickerson, R. R., Stein, A., Prasad, K. R., and Whetstone, J.: Wintertime $\mathrm{CO}_{2}, \mathrm{CH}_{4}$ and $\mathrm{CO}$ emissions estimation for the Washington DC/Baltimore metropolitan area using an inverse modeling technique, Environ. Sci. Technol., 54, 26062614, https://doi.org/10.1021/acs.est.9b06619, 2020a.

Lopez-Coto, I., Hicks, M., Karion, A., Sakai, R. K., Demoz, B., Prasad, K., and Whetstone, J.: Assessment of WRF PBL schemes in an urban region and comparison of the impact of the urban heat island, J. Appl. Meteorol. Clim., in review, 2020b.

Martin, C. R., Zeng, N., Karion, A., Dickerson, R. R., Ren, X., Turpie, B. N., and Weber, K. J.: Evaluation and environmental correction of ambient $\mathrm{CO} 2$ measurements from a low-cost NDIR sensor, Atmos. Meas. Tech., 10, 2383-2395, https://doi.org/10.5194/amt-10-2383-2017, 2017.

McKain, K., Down, A., Raciti, S. M., Budney, J., Hutyra, L. R., Floerchinger, C., Herndon, S. C., Nehrkorn, T., Zahniser, M. S., 
Jackson, R. B., Phillips, N., and Wofsy, S. C.: Methane emissions from natural gas infrastructure and use in the urban region of Boston, Massachusetts, P. Natl. Acad. Sci. USA, 112, 19411946, https://doi.org/10.1073/pnas.1416261112, 2015.

Mitchell, L. E., Lin, J. C., Bowling, D. R., Pataki, D. E., Strong, C., Schauer, A. J., Bares, R., Bush, S. E., Stephens, B. B., Mendoza, D., Mallia, D., Holland, L., Gurney, K. R., and Ehleringer, J. R.: Long-term urban carbon dioxide observations reveal spatial and temporal dynamics related to urban characteristics and growth, P. Natl. Acad. Sci. USA, 115, 2912-2917, https://doi.org/10.1073/pnas.1702393115, 2018.

Mueller, K., Yadav, V., Lopez-Coto, I., Karion, A., Gourdji, S., Martin, C., and Whetstone, J.: Siting Background Towers to Characterize Incoming Air for Urban Greenhouse Gas Estimation: A Case Study in the Washington, DC/Baltimore Area, J. Geophys. Res.-Atmos., 123, 2910-2926, https://doi.org/10.1002/2017JD027364, 2018.

Nehrkorn, T., Eluszkiewicz, J., Wofsy, S. C., Lin, J. C., Gerbig, C., Longo, M., and Freitas, S.: Coupled weather research and forecasting-stochastic time-inverted lagrangian transport (WRF-STILT) model, Meteorol. Atmos. Phys., 107, 51-64, https://doi.org/10.1007/s00703-010-0068-x, 2010.

Novelli, P. C., Masarie, K. A., Lang, P. M., Hall, B. D., Myers, R. C., and Elkins, J. W.: Reanalysis of tropospheric CO trends: Effects of the 1997-1998 wildfires, J. Geophys. Res.-Atmos., 108, 4464, https://doi.org/10.1029/2002JD003031, 2003.

O’Neill, B. C., Dalton, M., Fuchs, R., Jiang, L., Pachauri, S., and Zigova, K.: Global demographic trends and future carbon emissions, P. Natl. Acad. Sci. USA, 107, 17521-17526, https://doi.org/10.1073/pnas.1004581107, 2010.

Peters, W., Jacobson, A. R., Sweeney, C., Andrews, A. E., Conway, T. J., Masarie, K., Miller, J. B., Bruhwiler, L. M. P., Petron, G., Hirsch, A. I., Worthy, D. E. J., van der Werf, G. R., Randerson, J. T., Wennberg, P. O., Krol, M. C., and Tans, P. P.: An atmospheric perspective on North American carbon dioxide exchange: CarbonTracker, P. Natl. Acad. Sci. USA, 104, 1892518930, https://doi.org/10.1073/pnas.0708986104, 2007.

Pillai, D., Buchwitz, M., Gerbig, C., Koch, T., Reuter, M., Bovensmann, H., Marshall, J., and Burrows, J. P.: Tracking city $\mathrm{CO}_{2}$ emissions from space using a high-resolution inverse modelling approach: a case study for Berlin, Germany, Atmos. Chem. Phys., 16, 9591-9610, https://doi.org/10.5194/acp-169591-2016, 2016.

Ren, X. R., Salmon, O. E., Hansford, J. R., Ahn, D., Hall, D., Benish, S. E., Stratton, P. R., He, H., Sahu, S., Grimes, C., Heimburger, A. M. F., Martin, C. R., Cohen, M. D., Stunder, B., Salawitch, R. J., Ehrman, S. H., Shepson, P. B., and Dickerson, R. R.: Methane Emissions From the Baltimore-Washington Area Based on Airborne Observation: Comparison to Emissions Inventories, J. Geophys. Res.-Atmos., 123, 8869-8882, https://doi.org/10.1029/2018jd028851, 2018.

Richardson, S. J., Miles, N. L., Davis, K. J., Lauvaux, T., Martins, D. K., Turnbull, J. C., McKain, K., Sweeney, C., and Cambaliza, M. O. L.: Tower measurement network of in-situ $\mathrm{CO}_{2}, \mathrm{CH}_{4}$, and $\mathrm{CO}$ in support of the Indianapolis FLUX (INFLUX) Experiment, Elementa-Sci. Anthrop., 5, p. 59, https://doi.org/10.1525/elementa.140, 2017.

Salmon, O. E., Shepson, P. B., Ren, X., He, H., Hall, D. L., Dickerson, R. R., Stirm, B. H., Brown, S. S., Fibiger,
D. L., McDuffie, E. E., Campos, T. L., Gurney, K. R., and Thornton, J. A.: Top-Down Estimates of NOx and CO Emissions From Washington, DC-Baltimore During the WINTER Campaign, J. Geophys. Res.-Atmos., 123, 7705-7724, https://doi.org/10.1029/2018jd028539, 2018.

Santoni, G. W., Daube, B. C., Kort, E. A., Jiménez, R., Park, S., Pittman, J. V., Gottlieb, E., Xiang, B., Zahniser, M. S., Nelson, D. D., McManus, J. B., Peischl, J., Ryerson, T. B., Holloway, J. S., Andrews, A. E., Sweeney, C., Hall, B., Hintsa, E. J., Moore, F. L., Elkins, J. W., Hurst, D. F., Stephens, B. B., Bent, J., and Wofsy, S. C.: Evaluation of the airborne quantum cascade laser spectrometer (QCLS) measurements of the carbon and greenhouse gas suite $-\mathrm{CO}_{2}, \mathrm{CH}_{4}, \mathrm{~N}_{2} \mathrm{O}$, and $\mathrm{CO}$ - during the CalNex and HIPPO campaigns, Atmos. Meas. Tech., 7, 1509-1526, https://doi.org/10.5194/amt-7-1509-2014, 2014.

Sargent, M., Barrera, Y., Nehrkorn, T., Hutyra, L. R., Gately, C. K., Jones, T., McKain, K., Sweeney, C., Hegarty, J., Hardiman, B., Wang, J. A., and Wofsy, S. C.: Anthropogenic and biogenic $\mathrm{CO}_{2}$ fluxes in the Boston urban region, P. Natl. Acad. Sci. USA, 115, 7491-7496, https://doi.org/10.1073/pnas.1803715115, 2018.

Stein, A. F., Draxler, R. R., Rolph, G. D., Stunder, B. J. B., Cohen, M. D., and Ngan, F.: NOAA's Hysplit Atmospheric Transport and Dispersion Modeling System, B. Am. Meteorol. Soc., 96, 2059-2077, https://doi.org/10.1175/Bams-D-14-00110.1, 2015.

Sweeney, C., Karion, A., Wolter, S., Newberger, T., Guenther, D., Higgs, J. A., Andrews, A. E., Lang, P. M., Neff, D., and Dlugokencky, E.: Seasonal climatology of $\mathrm{CO}_{2}$ across North America from aircraft measurements in the NOAA/ESRL Global Greenhouse Gas Reference Network, J. Geophys. Res.-Atmos., 120, 5155-5190, 2015.

Turnbull, J., Guenther, D., Karion, A., Sweeney, C., Anderson, E., Andrews, A., Kofler, J., Miles, N., Newberger, T., Richardson, S., and Tans, P.: An integrated flask sample collection system for greenhouse gas measurements, Atmos. Meas. Tech., 5, 23212327, https://doi.org/10.5194/amt-5-2321-2012, 2012.

Turnbull, J. C., Karion, A., Davis, K. J., Lauvaux, T., Miles, N. L., Richardson, S. J., Sweeney, C., McKain, K., Lehman, S. J., Gurney, K. R., Patarasuk, R., Liang, J., Shepson, P. B., Heimburger, A., Harvey, R., and Whetstone, J.: Synthesis of Urban $\mathrm{CO}_{2}$ Emission Estimates from Multiple Methods from the Indianapolis Flux Project (INFLUX), Environ. Sci. Technol., 53, 287-295, https://doi.org/10.1021/acs.est.8b05552, 2019.

Verhulst, K. R., Karion, A., Kim, J., Salameh, P. K., Keeling, R. F., Newman, S., Miller, J., Sloop, C., Pongetti, T., Rao, P., Wong, C., Hopkins, F. M., Yadav, V., Weiss, R. F., Duren, R. M., and Miller, C. E.: Carbon dioxide and methane measurements from the Los Angeles Megacity Carbon Project - Part 1: calibration, urban enhancements, and uncertainty estimates, Atmos. Chem. Phys., 17, 8313-8341, https://doi.org/10.5194/acp-17-8313-2017, 2017.

Waxman, E. M., Cossel, K. C., Giorgetta, F., Truong, G.-W., Swann, W. C., Coddington, I., and Newbury, N. R.: Estimating vehicle carbon dioxide emissions from Boulder, Colorado, using horizontal path-integrated column measurements, Atmos. Chem. Phys., 19, 4177-4192, https://doi.org/10.5194/acp-194177-2019, 2019.

Welp, L. R., Keeling, R. F., Weiss, R. F., Paplawsky, W., and Heckman, S.: Design and performance of a Nafion dryer for continuous operation at $\mathrm{CO}_{2}$ and $\mathrm{CH}_{4}$ air monitoring sites, Atmos. 
Meas. Tech., 6, 1217-1226, https://doi.org/10.5194/amt-6-12172013, 2013.

WMO: 19th WMO/IAEA Meeting on Carbon Dioxide, Other Greenhouse Gases and Related Measurement Techniques (GGMT-2017), WMO/GAW Report No. 242, 2018.

Wong, C. K., Pongetti, T. J., Oda, T., Rao, P., Gurney, K. R., Newman, S., Duren, R. M., Miller, C. E., Yung, Y. L., and Sander, S. P.: Monthly trends of methane emissions in Los Angeles from 2011 to 2015 inferred by CLARS-FTS observations, Atmos. Chem. Phys., 16, 13121-13130, https://doi.org/10.5194/acp-1613121-2016, 2016.

Xueref-Remy, I., Dieudonné, E., Vuillemin, C., Lopez, M., Lac, C., Schmidt, M., Delmotte, M., Chevallier, F., Ravetta, F., Perrussel, O., Ciais, P., Bréon, F.-M., Broquet, G., Ramonet, M., Spain, T. G., and Ampe, C.: Diurnal, synoptic and seasonal variability of atmospheric $\mathrm{CO}_{2}$ in the Paris megacity area, Atmos. Chem. Phys., 18, 3335-3362, https://doi.org/10.5194/acp18-3335-2018, 2018.
Yadav, V., Duren, R., Mueller, K., Verhulst, K. R., Nehrkorn, T., Kim, J., Weiss, R. F., Keeling, R., Sander, S., Fischer, M. L., Newman, S., Falk, M., Kuwayama, T., Hopkins, F., Rafiq, T., Whetstone, J., and Miller, C.: Spatiotemporally Resolved Methane Fluxes From the Los Angeles Megacity, J. Geophys. Res.-Atmos., 124, 5131-5148, https://doi.org/10.1029/2018jd030062, 2019.

Yang, L., Jin, S., Danielson, P., Homer, C., Gass, L., Bender, S. M., Case, A., Costello, C., Dewitz, J., Fry, J., Funk, M., Granneman, B., Liknes, G. C., Rigge, M., and Xian, G.: A new generation of the United States National Land Cover Database: Requirements, research priorities, design, and implementation strategies, ISPRS J. Photogramm., 146, 108-123, https://doi.org/10.1016/j.isprsjprs.2018.09.006, 2018.

Zhao, C. L., Tans, P. P., and Thoning, K. W.: A high precision manometric system for absolute calibrations of $\mathrm{CO}_{2}$ in dry air, J. Geophys. Res.-Atmos., 102, 5885-5894, https://doi.org/10.1029/96JD03764, 1997. 